OPEN ACCESS

Edited by:

Christina Tsien,

Johns Hopkins Medicine,

United States

Reviewed by:

Jung Sun Yoo,

Hong Kong Polytechnic University,

SAR China

Bilgin Kadri Aribas,

Bülent Ecevit University, Turkey

*Correspondence:

Jingbo Wu

wib6147@163.com

Yue Chen

chenyue5523@126.com

${ }^{\dagger}$ These authors have contributed equally to this work and share first authorship

Specialty section:

This article was submitted to

Radiation Oncology,

a section of the journal

Frontiers in Oncology

Received: 27 June 2021

Accepted: 19 August 2021

Published: 07 September 2021

Citation:

Huang Y, Fan J, Li Y, Fu S, Chen Y and Wu J (2021) Imaging of Tumor Hypoxia With Radionuclide-Labeled

Tracers for PET.

Front. Oncol. 11:731503.

doi: 10.3389/fonc. 2021.731503

\section{Imaging of Tumor Hypoxia With Radionuclide-Labeled Tracers for PET}

\author{
Yuan Huang ${ }^{1+}$, Junying Fan ${ }^{1 \dagger}$, Yi $\mathrm{Li}^{1+}$, Shaozhi Fu ${ }^{1,2}$, Yue Chen ${ }^{2,3^{*}}$ and Jingbo Wu $\mathrm{Wu}^{1,2^{*}}$ \\ ${ }^{1}$ Department of Oncology, The Affiliated Hospital of Southwest Medical University, Luzhou, China, ${ }^{2}$ Department of \\ Oncology, Academician (Expert) Workstation of Sichuan Province, Luzhou, China, ${ }^{3}$ Nuclear Medicine and Molecular Imaging \\ key Laboratory of Sichuan Province, Department of Nuclear Medicine, The Affiliated Hospital of Southwest Medical \\ University, Luzhou, China
}

The hypoxic state in a solid tumor refers to the internal hypoxic environment that appears as the tumor volume increases (the maximum radius exceeds 180-200 microns). This state can promote angiogenesis, destroy the balance of the cell's internal environment, and lead to resistance to radiotherapy and chemotherapy, as well as poor prognostic factors such as metastasis and recurrence. Therefore, accurate quantification, mapping, and monitoring of hypoxia, targeted therapy, and improvement of tumor hypoxia are of great significance for tumor treatment and improving patient survival. Despite many years of development, PET-based hypoxia imaging is still the most widely used evaluation method. This article provides a comprehensive overview of tumor hypoxia imaging using radionuclide-labeled PET tracers. We introduced the mechanism of tumor hypoxia and the reasons leading to the poor prognosis, and more comprehensively included the past, recent and ongoing studies of PET radiotracers for tumor hypoxia imaging. At the same time, the advantages and disadvantages of mainstream methods for detecting tumor hypoxia are summarized.

Keywords: positron emission tomography (PET), cancer, hypoxia, imaging, radiotracer

\section{INTRODUCTION}

\section{Background}

The tumor vascular system is the main factor determining the internal microenvironment of a tumor during its growth and is responsible for the exchange of oxygen, metabolites, and energy

\footnotetext{
Abbreviations: ANG-2, angiopoietin-2; ANGPT2, angiopoietin 2; BOLD, blood oxygen level-dependent; CAIX, carbonic anhydrase IX; CKI, cyclin-dependent kinase inhibitor; CT, computed tomography; CTL, cytotoxic T-lymphocyte; CSC, cancer stem cell; DC, dendritic cell; EMT, epithelial-to-mesenchymal transition; EPR, electron paramagnetic resonance; FIH-1, factor inhibiting HIF-1; GLUT, glucose transporter; HIF, hypoxia-inducible factor; HNSCC, head and neck squamous cell carcinoma; HRE, hypoxia responsive element; Hsp, heat shock protein; IR, ionizing radiation; MDR, multi-drug resistance; MDSC, myeloid-derived suppressor cell; MRI, magnetic resonance imaging; NSCLC, non-small cell lung cancer; OPN, osteopontin; oxphos, oxidative phosphorylation; PDGF- $\beta$, platelet-derived growth factor- $\beta$; PEG, polyethylene glycol; PET, positron emission tomography; PHDs, prolyl-4-hydroxylases; PI3K, phosphoinositide 3-kinase; REOX, reoxygenated; ROS, reactive oxygen species; SPECT, single-photon emission computed tomography; SUV, standardized uptake value; TAM, tumor-associated macrophage; TGF,transforming growth factor; TNF,tumor necrosis factor; Treg, regulatory T-cell; VEGF, vascular endothelial growth factor; VHL, von Hippel Lindau.
} 
information between blood and tissue fluids. However, the vasculature of tumors differs from that of normal tissues. This structural difference increases the diffusion distance between the supplying vessels and tumor cells, forming a diffusion gradient and resulting in insufficient oxygen supply to the tumor cells that are away from the vessels, eventually leading to tissue hypoxia (1). As the volume of solid tumors continues to increase, especially when larger than 180-200 microns, coupled with the uncontrolled growth of tumor cells that consume high levels of oxygen and nutrients, tumor tissues will have insufficient local tissue perfusion or oxygen supply and lack of nutrients, resulting in the production of a series of acidic wastes and leading to extracellular acidosis. Collectively, these events ultimately result in tumor cells having a hypoxic microenvironment (2).

Hypoxia-inducible factor (HIF)-1 is a nuclear transcription factor that is widely present in mammalian cells. HIF-1 activates selected genes by transcription. These genes increase cell survival and proliferation to help cancer cells adapt to hypoxia by increasing angiogenesis, altering metabolism, degrading the extracellular matrix, inducing tumor cell dedifferentiation, and arresting the cell cycle (3-5). When the oxygen concentration is normal, HIF- $1 \alpha$ is ubiquitinated and can be rapidly hydrolyzed by the ubiquitin-proteasome system. Therefore, HIF expression in normoxic cells is low (6). However, hypoxia prevents the ubiquitination of HIF- $1 \alpha$ and induces an increase in the expression of HIF-1 $\alpha$ (7). The transcriptional activity of HIF-1 also increases with the degree of hypoxia, resulting in activation of the p53 gene and expression of the cyclin-dependent kinase inhibitor (CKI) (8). Simultaneously, HIF-1 $\alpha$ can also directly bind to the tumor suppressor gene p53 to promote p53dependent cell apoptosis (9). In hypoxic conditions, the inhibition of prolyl hydroxylase stabilizes HIF- $1 \alpha$, followed by its binding to HIF-1 $\beta$ and transportation to the nucleus. The transcriptional activator protein p300/CBP is recruited through a transcriptional activation region of subunit a, and then interacts with the hypoxia response element (HRE), composed of the core sequence $5^{\prime}$-RCGTG-3' of the promoter region of the target gene, such as carbonic anhydrase-IX (CA-IX). The downstream factors or enzymes are regulated and can then play a regulatory role (10) (Figure 1).

HIF can regulate vascular endothelial growth factor (VEGF), transforming growth factor (TGF), tumor necrosis factor (TNF), and angiopoietin-2 (ANG-2) receptor, among others (11), to

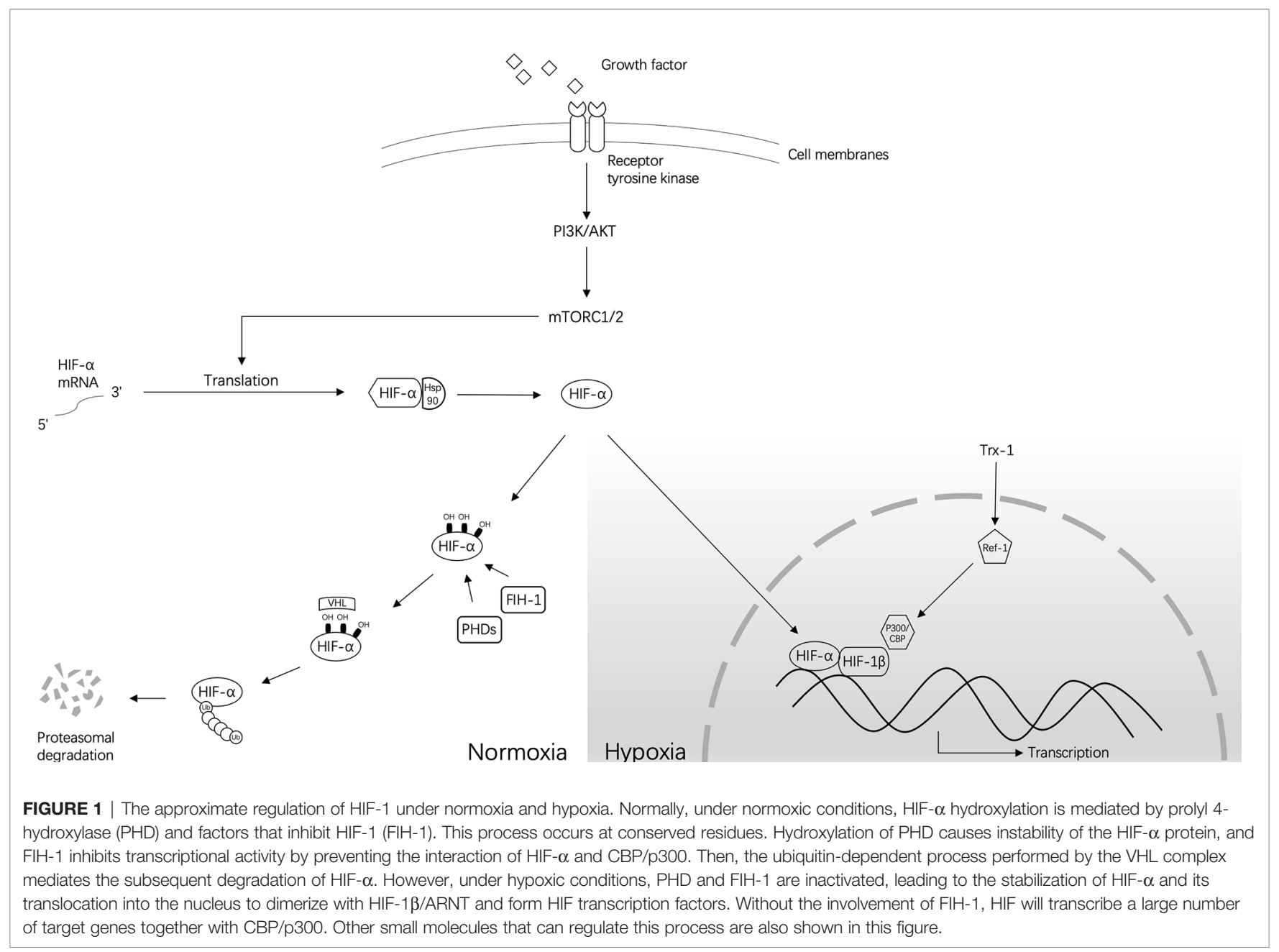


induce the proliferation of vascular endothelial cells. While inducing new blood vessels, HIF also regulates the vascular system of the host for the metastasis of tumor cells (12). Thus, the tumor can not only obtain nutrients and oxygen from the host through the new tumor blood vessels, but can also continuously deliver metastatic cells to the host through these blood vessels, while continuing to grow and inducing bloodvessel formation in other parts of the body, ultimately leading to tumor invasion and migration $(13,14)$. It is noteworthy that the formation of new blood vessels may lead to reoxygenation of hypoxic areas. Using current standard radiotherapy, hypoxic cells can also gradually become reoxygenated (REOX) during the treatment process due to the killing of the radiosensitive oxygen-consuming cells near the capillaries, as the remaining cells can obtain more nutrients and oxygen (15). Activated HIF can also induce the formation of tumor cell stemness and screen out more aggressive cells.

Additionally, increasing experimental evidence suggests that CA-IX plays a direct role in many tumor phenotypic characteristics caused by hypoxia and acidosis, including increased local adhesion during cell proliferation, unstable cell contact, tumor interstitial crosstalk, and maintaining the stem cell phenotype, signal transduction, and other cancer-related phenomena (16). Importantly, CA-IX is not expressed in most normal tissues except in the stomach and gallbladder epithelium (17). However, it is usually overexpressed in tumors and supports tumor cell migration and invasion. Inhibiting the catalytic activity of CA-IX can significantly improve chemotherapeutic sensitivity or radiosensitivity. Similarly, inhibiting CA-IX can enhance the anti-angiogenic effect of anti-VEGF antibodies (18).

\section{Significance}

Under hypoxic conditions, up-regulated HIF can regulate a variety of cancer phenotypes, causing various adverse changes in tumors and tissues (Figure 2).

Hypoxia can cause genetic damage. The rapid change in oxygen concentration produces free radicals, which act on tissue cells and cause DNA damage (19). Moreover, hypoxia may lead to the overexpression of tumor suppressor genes, proapoptotic factors, and anti-apoptotic factors to salvage damaged cells, but may make these cells polyploid. A study by Nelson et al. (20) shows that these cells have certain defects in their inherent apoptotic pathways, which are important signs of cancer and precancer.

The most important biological effect caused by hypoxia is resistance to radiotherapy and chemotherapy, which is directly related to disease prognosis. Molecular oxygen is very important for the sensitivity of radiotherapy. In conventional photon-based radiotherapy or light ion therapy, such as those using protons, oxygen has a high electron affinity and plays a central role in the fixation process $(21,22)$. Hypoxia reduces the ability of the drug to produce free oxygen radicals, resulting in hypoxic cells that are less sensitive to chemotherapy.

Another interesting phenomenon is that when the hypoxic state causes cell death, the migration of tumor-associated macrophages (TAM) to the hypoxic area is inhibited, thereby preventing TAM from removing dead and damaged cells. Other effects of TAM include inhibition of the immune response of the body to tumor cells and inhibition of the activation of adjacent macrophages. These phenomena promote angiogenesis and lymphangiogenesis, thereby promoting tumor growth, migration, and transformation $(23,24)$. Hypoxia-related TAM can upregulate HIF-1 and HIF-2 expression both in vivo and in vitro (25).

E-cadherin is an important intercellular adhesion molecule that mainly maintains the integrity and polarity of epithelial cells. Loss of E-cadherin is a sign of tumor epithelial-to-mesenchymal transition (EMT) in tumor cells and is related to hypoxiainduced HIF activation.

\section{Definition}

There are considerable differences in the degree of hypoxia among different tumor types; thus, it is impossible to propose a definite value to define hypoxia. The currently recognized "gold standard" is to measure the distribution of the partial pressure of oxygen ( $\mathrm{pO} 2$ ) using polarographic electrodes, but this method is invasive and greatly limits its use in tumor determination. As the oxygen requirement of tissues is met by blood, a method of responding to hypoxia by measuring the vascular supply was proposed. Cryophotometry or magnetic resonance imaging (MRI) to measure blood oxygen saturation, or MRI, computed tomography (CT), or positron emission tomography (PET) to measure tumor perfusion have been widely used (Table 1). However, vascular supply is not the only factor that causes hypoxia in cells and tissues; thus, monitoring of the vascular supply alone cannot completely determine hypoxia (50). Later, it was discovered that the expression of certain genes and proteins changes during hypoxia. Therefore, it was proposed that the state of hypoxia could be determined by measuring the levels of the endogenous markers. These principal markers include HIF-1, CA-IX, glucose transporter (GLUT)-1 and -3, and osteopontin $(\mathrm{OPN})$. However, some reactions that are not related to hypoxia can also lead to upregulation of the endogenous markers. Some studies have reported that reactive oxygen species, cancerspecific mutations, and changes in signal transduction pathways can cause these changes even in normoxic conditions (51).

However, the most widely used method for detecting hypoxia is based on PET/SPECT imaging. For example, foreign substances (imidazole drugs, cytarabine, or other substances) are labeled with radionuclides or fluorescent probes and used as tracers with specific chemical properties to target hypoxic areas within the tumor.

To summarize, pre-monitoring of hypoxic information before tumor diagnosis or treatment is extremely important in selecting accurate and effective individualized treatments and monitoring the efficacy and prognosis. As PET is more commonly used in a clinical setting for tumor diagnosis, in this review, we have focused and conducted a thorough evaluation on several methods that use markers in PET imaging to detect hypoxia. This study sheds light on the timely intensive treatment 


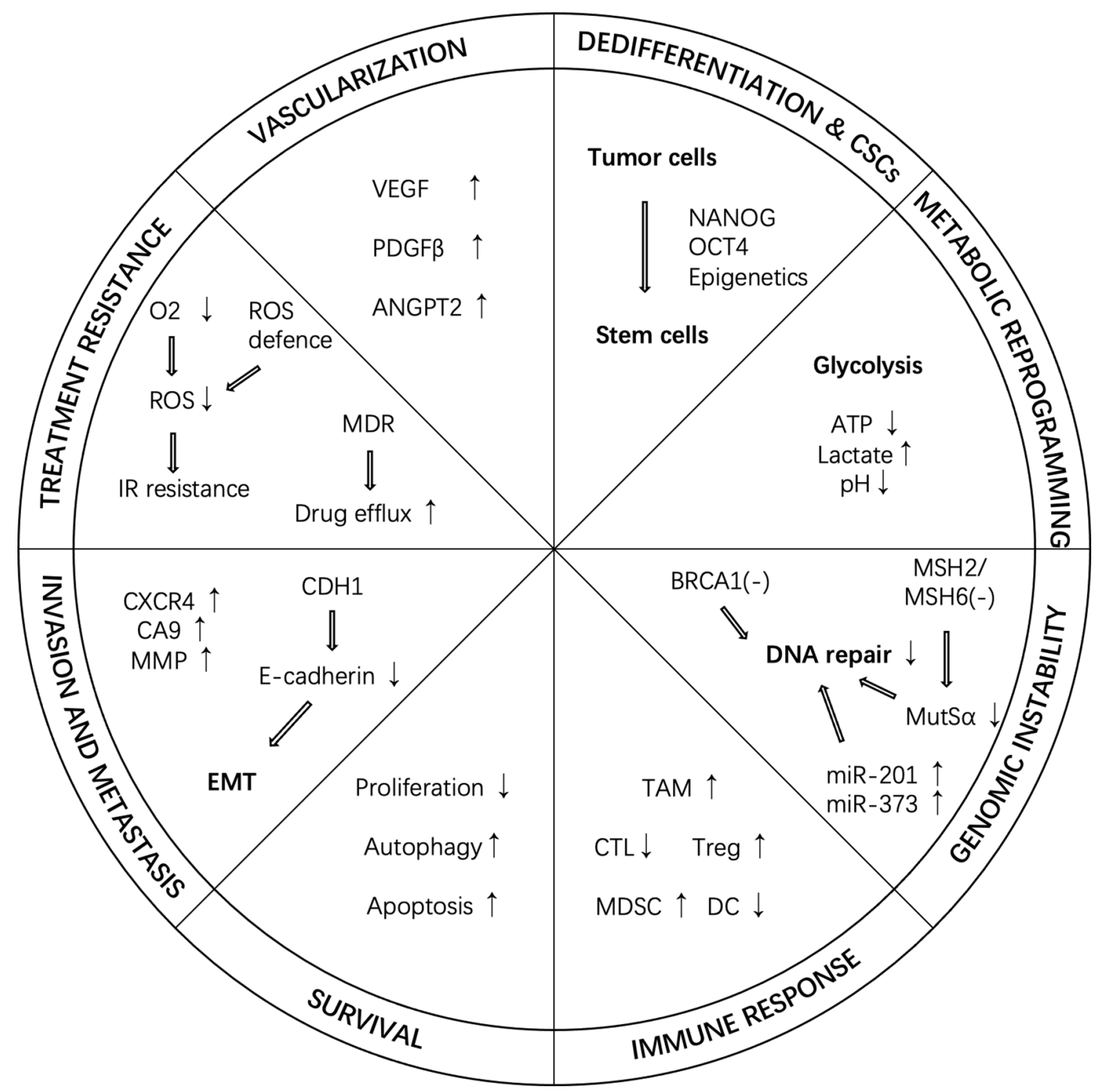

FIGURE 2 | Cancer hallmarks regulated by HIF under hypoxic conditions. In hypoxic conditions, HIF can regulate a variety of cancer phenotypes, such as vascularization, dedifferentiation, metabolic reprogramming, genome instability, immune response, survival, invasion and metastasis, and treatment resistance. ANGPT2, angiopoietin 2; CTL, cytotoxic T-lymphocyte; CSC, cancer stem cell; DC, dendritic cell; IR, ionizing radiation; MDR, multi-drug resistance; MDSC, myeloidderived suppressor cell; PDGF- $\beta$, platelet-derived growth factor- $\beta$; ROS, reactive oxygen species; TAM, tumor-associated macrophage; Treg, regulatory T-cell; VEGF, vascular endothelial growth factor.

methodologies to overcome the resistance caused by hypoxia and prevent local recurrence.

\section{MAIN METHOD}

Since 1981, misonidazole (Miso) was introduced as the first marker for the identification of tumor hypoxia based on molecular imaging. Miso was labeled with ${ }^{14} \mathrm{C}$ for autoradiography to detect tumor hypoxia (52). Subsequently, two important PET tracer categories, 18F-labelled nitroimidazoles and $\mathrm{Cu}$-labelled
diacetyl-bis(N4-methylthiosemicarbazone) analogs, have been developed to specifically study the areas of tumor hypoxia (53).

\section{${ }^{18} \mathbf{F}$}

Janet Rasey and her colleagues at the University of Washington first proposed the noninvasive imaging of hypoxia by PET (54). They synthesized 18F-fluoromisonidazole and then verified its feasibility as a PET hypoxia tracer in several models of human tumors. Since then, researchers have extensively explored the possibility of using ${ }^{18} \mathrm{~F}$-labeled compounds as hypoxia tracers (Figure 3). 
TABLE 1 | Main methods of hypoxia assessment.

Advantage

Disadvantage

Direct measurements

Oxygen electrodes Insert the electrode needle into the (26-31) (Eppendorf tumor for multiple measurements probes)

OxyLite (32)

Continuous measurement at a single spot in a tumor.

\section{Indirect}

\section{measurements}

EPR (33-35)

Paramagnetic probes altered by the surrounding paramagnetic $\mathrm{O}_{2}$ in electron relaxation procedure

MRI-BOLD (36-40) Determines changes in the level of oxygenated hemoglobin

MRI Fluorine (41) Measures change in relaxivity of fluorinated probes in the presence of oxygen

Redox-activated Examines change in proton relaxivity MRI contrast agents (42-44) PET due to reactive oxygen species with excitation of exogenous radicals Nitroimidazole: Radioisotope labeled nitroimidazole trapped in hypoxic cells (45-47)

Cu-ATSM: Reduced metal complexes binding to macromolecules and trapped in hypoxic cells (48)

SPECT (49) Differential accumulation of SPECT tracers in areas of low oxygen concentration
Directly measure the partial pressure of oxygen at multiple points

Closely related to the clinical outcomes of a small number of tumor types

Dynamic measurement (within several hours)

No $\mathrm{O}_{2}$ consumption; dynamic measurement

$\mathrm{No}_{2}$ consumption; high temporal resolution

No $\mathrm{O}_{2}$ consumption; dynamic measurement

$\mathrm{No} \mathrm{O}_{2}$ consumption; quantitative

Noninvasive; high sensitivity; quantitative; assessment of the entire tumor volume; spatial mapping of hypoxia; serial assessment over time

Noninvasive; assessment of the entire tumor volume; spatial mapping of hypoxia; serial assessment over time
Invasive and technically demanding. Suitable only for accessible tumors; risk of modifying oxygen concentration

Invasive; not approved for clinical use

Existing clinical equipment is unsuitable

Easy to be disturbed; unsuitable for tissue hypoxia

Existing clinical equipment is unsuitable

Relatively low spatial resolution; requires a high concentration of contrast media

Lack of a suitable trace; prone to false-positive results; ingested in normal tissues; unsatisfactory spatial resolution and tumor background ratio

Resolution is limited; fewer agents than those available for PET; difficulties in quantifying hypoxia<smiles>O=[N+]([O-])c1nccn1CC(O)C[18F]</smiles>

18F-FMISO<smiles>O[C@H]1CO[C@H](C[18F])[C@@H]1O</smiles>

${ }^{18} \mathrm{~F}-\mathrm{FAZA}$<smiles>O=C(Cn1ccnc1[N+](=O)[O-])NCC(F)(F)C(F)(F)[18F]</smiles>

${ }^{18} \mathrm{~F}-\mathrm{EF} 5$<smiles>O=[N+]([O-])c1nccn1Cc1cn(C(CO)C[18F])nn1</smiles>

${ }^{18} \mathrm{~F}-\mathrm{HX} 4$
${ }^{18} \mathrm{~F}-\mathrm{RP}-170$<smiles>O=[N+]([O-])c1nccn1COC(CO)C[18F]</smiles>

트루

FIGURE 3 | Structures of clinically used $\left[{ }^{18} \mathrm{~F}\right]$-labeled nitroimidazole compounds. 


\section{Nitroimidazole}

2-Nitroimidazole was originally developed as a radiosensitizer for hypoxic cells and proposed as a hypoxia marker in the 1970s (55). The reduction of nitroimidazole in cells is achieved by nitroreductases. The first one-electron reduction to a nitro group is reversible and the reduced substance is easily reoxidized by molecular oxygen (56). Therefore, substances reduced under aerobic conditions can be quickly reoxidized and can diffuse outside the cell without being retained in normal cells. However, under hypoxic conditions, the free nitro radicals are further reduced in cells, undergo protonation, combine with intracellular macromolecules, and are irreversibly retained in hypoxic cells (Figure 4). These radicals are not encountered in apoptotic or necrotic cells (57-59).However, the accumulation of nitroimidazole compounds in tumor cells is not only affected by hypoxia, but also by many other aspects, such as the expression level of multidrug resistance-associated protein 1 (MRP1) $(60,61)$. It is reported that tumor cells pretreated with MRP1 inhibitors have significantly higher radioactivity than cells not treated with inhibitors. At the same time, the $S_{U V}$ mean ratio in tumors of mice in the treatment group is significantly higher than that of control mice in vivo PET studies. Therefore, it was found that MRP1 inhibitors can increase the accumulation of ${ }^{18} \mathrm{~F}$-FMISO in hypoxic cells (62). In other words, during this type of chemotherapy, it may lead to an overestimation of tumor hypoxia.

\section{${ }^{18}$ F-FMISO}

Over the years, several fluorinated nitroimidazole-based labels have been developed for PET imaging. Currently, the most commonly used PET hypoxia tracer used clinically and in research is ${ }^{18} \mathrm{~F}$-fluoroimidazole $\left({ }^{18} \mathrm{~F}\right.$-FMISO $)(63,64)$. It is also the first drug to be clinically tested (65) and has been successfully used in glioma (66), breast cancer (67), head and neck tumors $(68,69)$, lung cancer $(70)$, and other models to reflect hypoxia, and also used to stratify patients for radiotherapy. However, after intravenous injection, only medium contrast images are obtained owing to its high relative lipophilicity and slow penetration from the blood and passive diffusion, which results in a relatively low uptake (71). Compared with conventional imaging methods such as CT and MRI, ${ }^{18} \mathrm{~F}$-FMISO PET has a lower resolution (5-7 $\mathrm{mm})$ (72). These limitations of ${ }^{18} \mathrm{~F}$-FMISO have led to the development of second-generation drugs with improved pharmacokinetic properties.

\section{${ }^{18}$ F-FAZA}

The second-generation representative drug ${ }^{18}$ F-FAZA [1-(5fluoro-5-deoxy- $\alpha$-D-arabinofuranosyl)-2-nitroimidazole)] has better hydrophilicity and can enhance the signal-to-noise ratio.

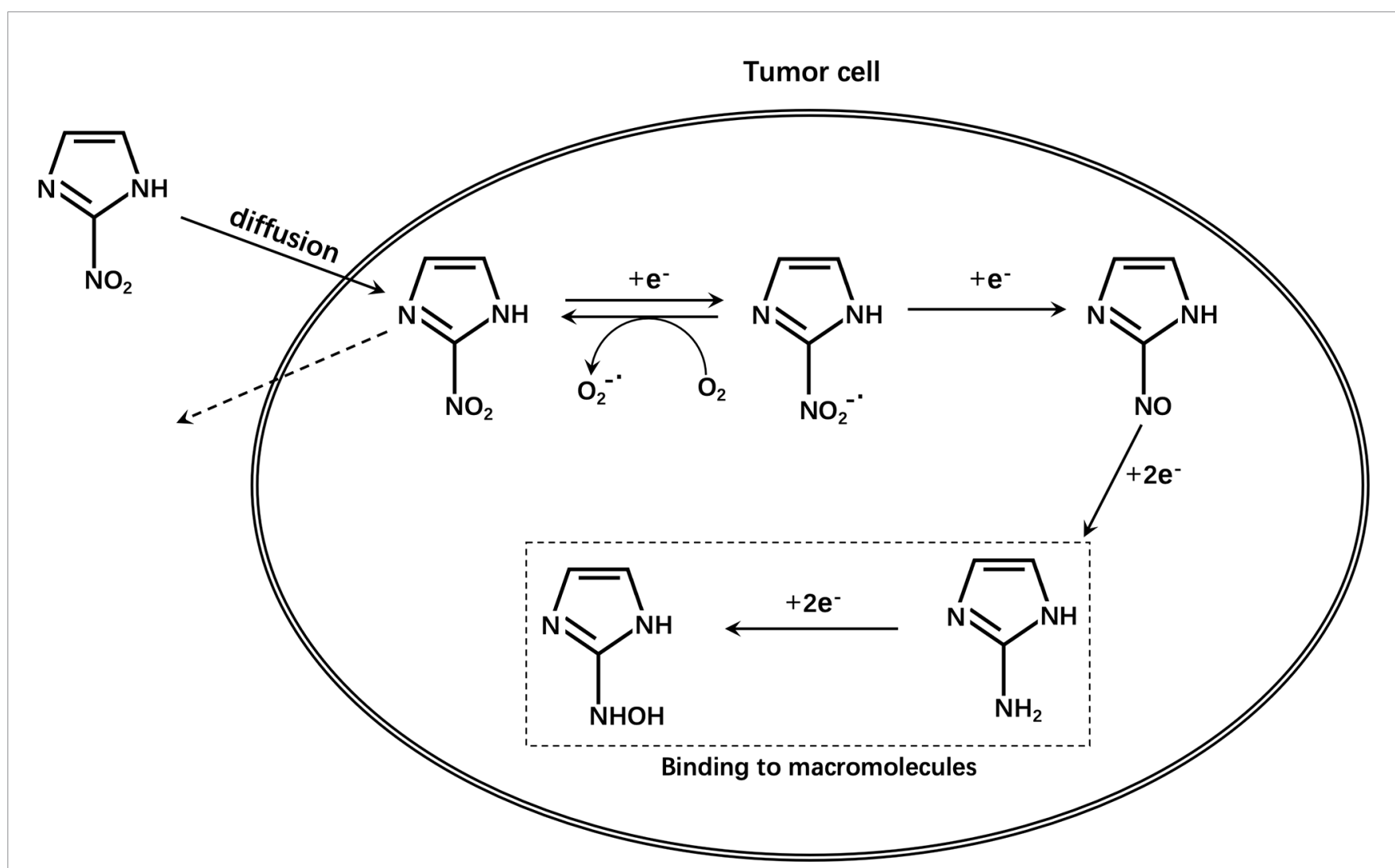

FIGURE 4 | Schematic diagram of the mechanism of nitroimidazole compounds. 
Its low lipophilicity leads to faster clearance of unbound drugs by the blood, which can improve hypoxia-normoxia contrast at an early point in time. In preclinical animal studies, the head-tohead comparison of ${ }^{18} \mathrm{~F}-\mathrm{FAZA},{ }^{124} \mathrm{I}-\mathrm{IAZA}$, and ${ }^{18} \mathrm{~F}$-MISO showed that ${ }^{18} \mathrm{~F}$-FAZA had faster vascular clearance than that of 18F-FMISO after 3 hours of injection. Recently, clinical studies have successfully evaluated the feasibility of ${ }^{18} \mathrm{~F}$-FAZA in hypoxic imaging of brain glioma (73) and lymphoma (73); lung $(74,75)$, head and neck $(76,77)$, cervical spine $(78)$, and cervical tumors (79); rhabdomyosarcoma (80); and rectal tumors (81). Generally speaking, 18-FAZA has better application values compared with ${ }^{18}$ F-FMISO.

\section{${ }^{18}$ F-FETNIM}

${ }^{18}$ F-Fluoroerythronitromidazole (FETNIM) also has better hydrophilicity than ${ }^{18} \mathrm{~F}$-FMISO, allowing for rapid renal clearance and low liver absorption, which can also explain the negative positive relationship between tumor blood flow and initial tumor ${ }^{18}$ F-FETNIM absorption (82). Clinical studies in esophageal cancer (83), head and neck tumors (84-86), and cervical cancer (87) have shown that the tumor-to-blood ratio calculated by imaging at $2 \mathrm{~h}$ pi is $1.4-2.48$ within the range, and that high tissue uptake of FETNIM indicates reduced progression-free and overall survival. Although ${ }^{18}$ F-FETNIM can also be used in imaging studies to determine hypoxia in lung cancer $(88,89)$, some studies indicate that the uptake of ${ }^{18} \mathrm{~F}$ FMISO in the tumor/non-tumor ratio is significantly higher than that of ${ }^{18}$ F-FETNIM. Therefore, whether ${ }^{18}$ F-FETNIM has a better application value than ${ }^{18}$ F-FMISO is still debatable (90).

\section{${ }^{18}$ F-RP-170}

Another ${ }^{18} \mathrm{~F}$-labeled 2-nitroimidazole compound, ${ }^{18} \mathrm{~F}-\mathrm{RP}-170$, has been used to study patients with glioma, and the average tpO2 in the high uptake area has been reported to be significantly lower than that in the low uptake area. In the high uptake area, a significant negative correlation between the standardized uptake value (SUV) and tpO2 has been noted, whereas the HIF- $1 \alpha$ index in the high uptake area is significantly higher than that in the low uptake area. These findings are suggestive of the low oxygen selectivity of ${ }^{18}$ F-FRP-170 $(91,92)$. Studies on brain tumors (93) and lung cancer (94) show that the SUV in hypoxic tissue is higher than that in normal tissue. Compared with ${ }^{18} \mathrm{~F}$-FMISO, the shorter time interval before scanning and improved hypoxic contrast may make it more suitable for research and use in clinical imaging.

\section{${ }^{18}$ F-EF5}

${ }^{18}$ F-EF5 was studied as a PET tracer in 2001. Compared with many other hypoxia tracers, ${ }^{18} \mathrm{~F}$-EF5 has a higher octanol-water partition coefficient, which enables higher cell membrane permeability and longer plasma half-life (95), which can improve the uniformity of tumor uptake and tracer distribution. In the study of patients with head and neck squamous cell carcinoma (HNSCC), the median tumor-tomuscle ${ }^{18} \mathrm{~F}$-EF5 uptake ratio (T/M) was found to increase over time and reported as 1.38 (range, 1.1-3.2) after $3 \mathrm{~h}$ of tracer injection (96). The ability of ${ }^{18} \mathrm{~F}-\mathrm{EF} 5$ to detect hypoxia is encouraging. It was also found in preclinical studies that ${ }^{18} \mathrm{~F}$ EF5 PET could predict the response to graded radiotherapy in tumor models (97); however, its marking chemistry is more complicated by comparison.

\section{${ }^{18} \mathrm{~F}-\mathrm{HX} 4$}

A third-generation nitroimidazole tracer $\left({ }^{18} \mathrm{~F}-\mathrm{HX} 4\right)$ (98) has been developed in recent years. A 1,2,3-triazole moiety is introduced using simple click chemistry to make the compound more hydrophilic, which, at the same time, also increases its renal clearance (99). These characteristics of ${ }^{18} \mathrm{~F}$ HX4 help in reducing the background signal faster, thereby improving the signal-to-noise ratio (98). Preliminary studies have shown that compared with ${ }^{18} \mathrm{~F}$-FMISO and ${ }^{18} \mathrm{~F}-\mathrm{FAZA}$, ${ }^{18} \mathrm{~F}-\mathrm{HX} 4$ has a higher maximum tumor-to-blood ratio with a half-life of about $3 \mathrm{~h}$ (100). In addition, a piece of evidence that can prove that ${ }^{18} \mathrm{~F}-\mathrm{HX} 4$ will accumulate in hypoxic areas is the observation of a strong and significant spatial relationship between the distribution of ${ }^{18} \mathrm{~F}-\mathrm{HX} 4$ and pyridimidazole positivity and CA-IX positivity $(98,99,101)$. In non-small cell lung cancer (NSCLC) (102), HNSCC $(103,104)$, and esophageal and pancreatic cancers (105), a clear correlation with ${ }^{18}$ FDG is observed, which is important however, better repeatability (106). Therefore, ${ }^{18} \mathrm{~F}-\mathrm{HX} 4$ is a progressive next-generation tracer that can be used as a tool for monitoring treatment responses and radiotherapy planning.

\section{${ }^{60-64} \mathrm{Cu}$ \\ Copper (Cu)-diacetyl-bis (N4- methylthiosemicarbazone) (Cu-ATSM)}

Another widely studied class of agents is the $\mathrm{Cu}$ complex with diacetyl-bis(N4-methylthiosemicarbazone) (ATSM) ligand, among which ATSM is the prototype (Figure 5). Fujibayashi

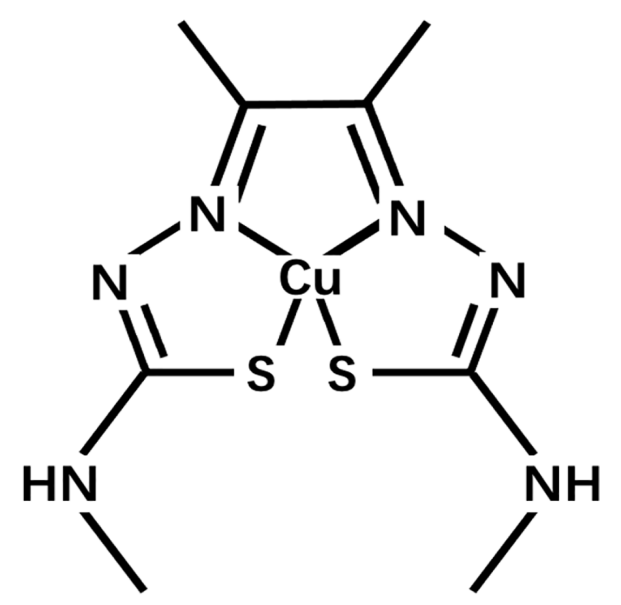

\section{Cu-ATSM}

FIGURE 5 | Structure of CU-ATSM 
et al. from Eukui Medical School in Japan (107) and Holland et al. from Washington University, St. Louis were the first to study the potential of these compounds in hypoxia imaging (108). Fujibayashi et al. used the ${ }^{60-64} \mathrm{Cu}$ isotope to label some compounds such as ATSM and used the synthesized ${ }^{62} \mathrm{Cu}$ ATSM to study cardiac perfusion in a rat model. Their findings suggested that ${ }^{62} \mathrm{Cu}$-ATSM could accumulate during hypoxia. Similarly, their studies on ${ }^{64} \mathrm{Cu}$-ATSM, ${ }^{18} \mathrm{~F}$-FMISO, and ${ }^{64} \mathrm{Cu}$-PTSM in EMT-6 tumor cells showed that ${ }^{64} \mathrm{Cu}-\mathrm{ATSM}$ and ${ }^{18}$ F-FMISO could differentially accumulate in tumors. In hypoxia, the accumulation was region specific and only ${ }^{64} \mathrm{Cu}-$ PTSM was evenly distributed in the tumor (109). Cu-ATSM was first evaluated in humans as a radiodiagnostic agent for imaging lung cancer in the year 2000 (110), following successful preclinical trials (111-113).

Unfortunately, the exact mechanism of Cu-ATSM hypoxia selectivity is unclear and controversial and has conflicting findings $(114,115)$. In conclusion, based on initial research, it is believed that $\mathrm{Cu}(\mathrm{II})$-ATSM will diffuse rapidly into cells owing to its high membrane permeability and low redox potential, and will be metabolized by NADH/NADPH in the mitochondria that are dysfunctional due to hypoxia. Under normoxic conditions,
$\mathrm{Cu}(\mathrm{I})-\mathrm{ATSM}$ is reversibly oxidized to $\mathrm{Cu}(\mathrm{II})$-ATSM and diffuses out of the cell. In contrast, under hypoxic conditions, the $\mathrm{Cu}(\mathrm{I})$ ATSM complex is irreversibly retained in the cell. Since $\mathrm{Cu}(\mathrm{I})$ ATSM is far less stable than $\mathrm{Cu}(\mathrm{II})$-ATSM, under the mediation of $\mathrm{pH}$ and other conditions, copper dissociates from the complex to form $\mathrm{ATSMH}_{2}$, causing radioactive copper to remain in the cell $(116,117)$ (Figure 6).

Compared with ${ }^{18}$ F-FDG and fluorine-based hypoxic PET tracer, radiolabeled $\mathrm{Cu}-\mathrm{ATSM}$ can specifically accumulate in the hypoxic areas of the tumor and form a certain difference. Moreover, Cu-ATSM exhibits better pharmacokinetics and signal-to-noise ratio, is not taken up by the bladder, and does not show any interference (118-122) (Table 2).

Although its retention mechanism in hypoxic cells is still controversial, Cu-ATSM has been used as a PET tracer to study tumor hypoxia for head-and-neck $(153,154)$ lung $(155,156)$, cervical $(157,158)$, and rectal tumors (159), and gliomas (160). Studies have shown that Cu-ATSM has other benefits when used for hypoxia imaging, such as in the staging and detection of recurrent prostate cancer $(120,121)$; as an effective indicator to predict neoadjuvant chemoradiotherapy and survival rate of patients with rectal cancer (159); as an indicator of treatment

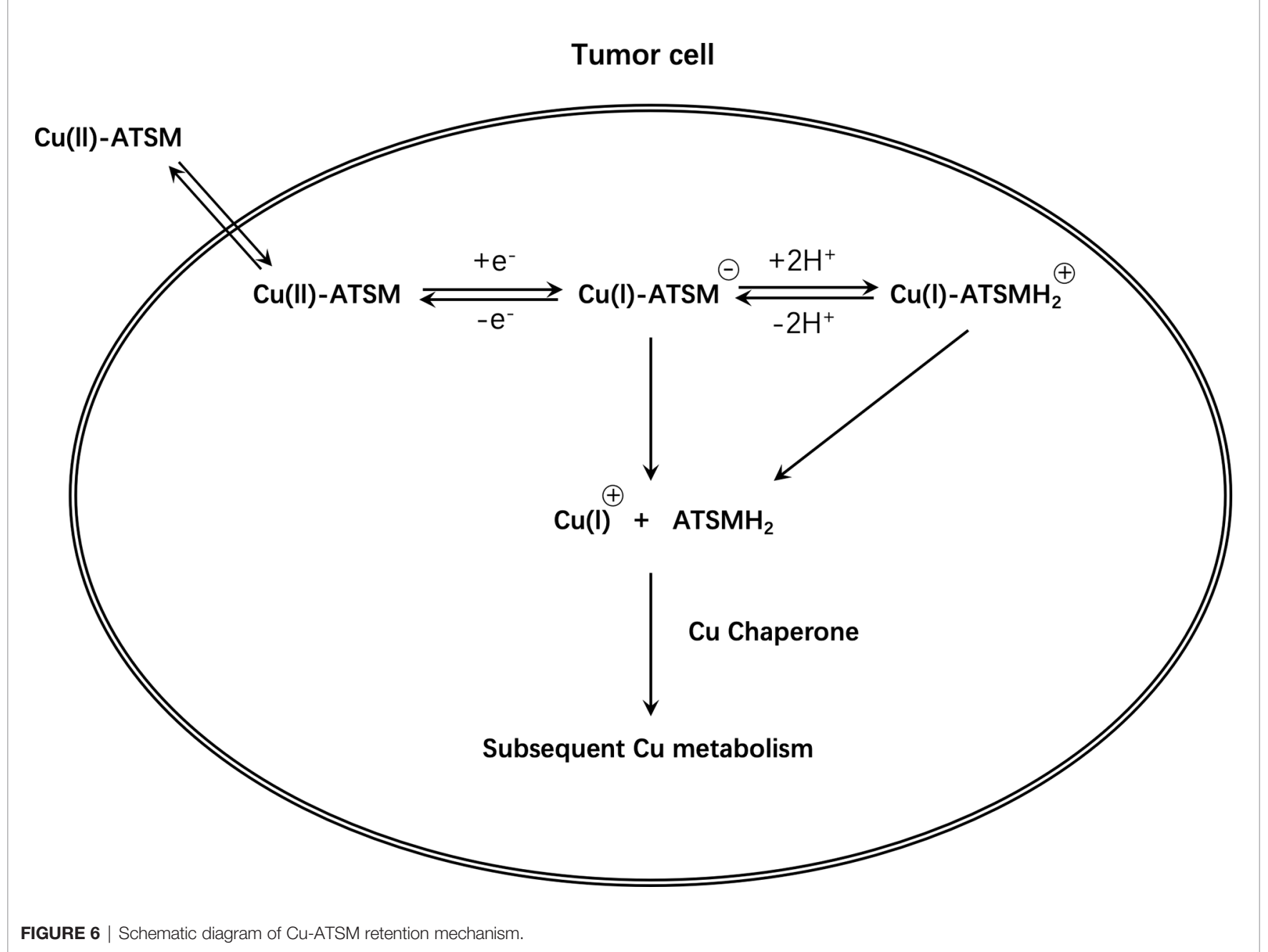


TABLE 2 | Comparison of ${ }^{18}$ F-labeled nitroimidazoles and Cu-labeled diacetyl-bis(N4-methylthiosemicarbazone) highlighting the characteristics of the ideal hypoxia PET tracer.

\begin{tabular}{|c|c|c|c|c|c|c|c|}
\hline & ${ }^{18} F$-FMISO & ${ }^{18} F-F A Z A$ & ${ }^{18}$ F-FETNIM & ${ }^{18} F-R P-170$ & ${ }^{18} F-E F 5$ & ${ }^{18} \mathrm{~F}-\mathrm{HX} 4$ & Cu-ATSM \\
\hline 1. Hypoxia specificity & $(123-125)$ & $(123)$ & $(123)$ & $(91)$ & $(95)$ & $(123,126)$ & $(109,127)$ \\
\hline 2. Well-defined mechanism of retention & $(128)$ & $(129)$ & $(130)$ & $(1)$ & $(131)$ & $(100)$ & $(116,117)$ \\
\hline 3. Homogenous distribution and rapid clearance & $(123)$ & $(123)$ & $(123)$ & $(132)$ & $(96)$ & $(106,123$ & $(113)$ \\
\hline 4. Little dependency on factors that co-vary with hypoxia & $(133)$ & $(134)$ & $(135)$ & $(92)$ & (96) & $(136)$ & $(137)$ \\
\hline 5. Stability against non-hypoxic metabolism & $(138)$ & & & $(92)$ & $(95)$ & $(123,126)$ & $(139)$ \\
\hline 6. Suitable acquisition time & $(140)$ & $(141)$ & $(142)$ & $(91)$ & $(96)$ & $(141)$ & $(111,112)$ \\
\hline 7. Easy to synthesize and readily available & $(142)$ & $(143)$ & $(142)$ & $(143)$ & $(13)$ & $(142,14)$ & $(16)$ \\
\hline 8. Amenable dosimetry profile & $23,14)$ & $(123)$ & $(123,144)$ & $(9-1)$ & $(145)$ & $(123,14)$ & \\
\hline 9. Repeatability in spatial uptake & $(146)$ & $(147)$ & $(148)$ & $(91)$ & $(149)$ & $(150)$ & $(1+1)$ \\
\hline 10. Effective regardless of tumor type and stage & $(123)$ & $(12)$ & $(123)$ & $(67,142)$ & $(151)$ & & \\
\hline
\end{tabular}

green (Yes= characteristics met); red (No= characteristics not met); blue = no consensus; blank = no data.

Detailed characteristics description: 1. Hypoxia is specifically retained in areas with low pO2 levels, but is not retained by normoxic or necrotic cells; 2 . The retention mechanism of cells should be clearly defined and independent of cell type; 3. It should be hydrophilic enough to avoid membrane isolation, but also lipophilic enough to enter cells and allow uniform tissue distribution, and faster clearance from systemic circulation and normoxic tissues; 4 . It's pharmacokinetic characteristics and tissue distribution do not depend on parameters that may change with hypoxia, such as blood flow or pH; 5 . It should have high stability against non-hypoxia specific metabolism in vivo; 6 . The tissue kinetics should be suitable for imaging within the time frame allowed by clinical conditions; 7. It should be easy to synthesize and readily available; 8 . It should have a amenable dosimetry profile; 9. It should be epeatable to allow detection of hypoxia and return to normal oxygen; 10. It should be effective for multiple tumor types (123).

response in head and neck cancer (161), and in brain tumors (162). In addition, due to its special radioactivity, many reports have highlighted its use as an effective radiotherapy agent. Since treatment is not within the scope of this review, it has not been discussed here $(163,164)$.

In summary, the above-mentioned studies show that the use of radiolabeled Cu-ATSM complex in PET examination is feasible and that other benefits to the treatment of patients are also possible (Table 3). Although the mechanism of action is unclear, it is still worth pursuing in-depth research and development on this compound.

\section{EXISTING RESEARCH}

\section{${ }^{68} \mathrm{Ga}$}

${ }^{68} \mathrm{Ga}\left(\mathrm{t}_{1 / 2}=68 \mathrm{~min}, 89 \% \mathrm{~b}+, \mathrm{Eb}+\mathrm{max}=1.92 \mathrm{MeV}, 11 \% \mathrm{EC}\right)$ is a generator-produced radionuclide that offers excellent coordination chemistry with several bifunctional chelating agents and provides rapid radiolabeling over a range of $\mathrm{pH}$ (191-193). Therefore, ${ }^{68} \mathrm{Ga}$ has been preferentially studied in hypoxic PET. For example, Sudhakara et al. developed ${ }^{68} \mathrm{Ga}$ labeled agents based on mono-, bis-, and tris-nitroimidazole conjugates with the chelating agent 1,4,7-triazacyclononane1,4,7-tris[methyl(2-carboxyethyl)phosphinic acid] (TRAP), to obtain a series of ${ }^{68} \mathrm{Ga}$-labeled compounds. The radiochemical yields were extremely high and the uptake of tumor models in in vivo experiments revealed its remarkable ability to target hypoxic areas (194). Recently, Yoichi Shimizu et al. also confirmed that the ${ }^{68} \mathrm{Ga}$ marker could help in the visualization of tumor tissues and hypoxic areas within $2 \mathrm{~h}$ of intravenous injection (195). In short, studies on lung $(196)$ and colon cancers $(197,198)$ show that on the basis of the ease in production, ${ }^{68} \mathrm{Ga}$-labeled hypoxia tracers are comparable to traditional ${ }^{18} \mathrm{~F}$-labeled tracers.

\section{4/125/131 I}

Radioactive iodine is a commonly used radiotherapy agent for the diagnosis and treatment of thyroid diseases. The characteristics of its radiation make it well-sought after for radioimmunotherapy (199). Radioactive iodine isotopes play a role in the field of hypoxia imaging as they can be used to label various substrates that can target hypoxic regions. For example,

TABLE 3 | Partial summary of clinical imaging studies of hypoxia tracers.

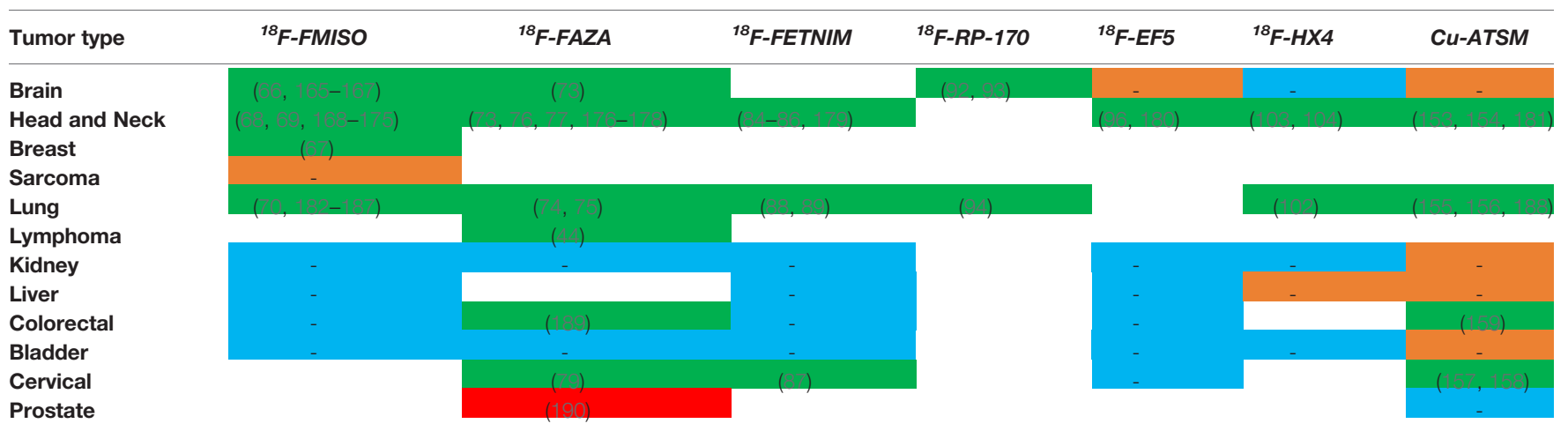

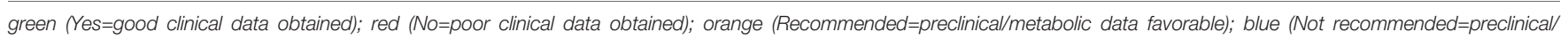
metabolic data unfavorable); blank=no data. Only relevant references in green and red categories are shown. 
${ }^{123}$ I-IAZA is the most common radiotracer with a chemical structure similar to that of ${ }^{18} \mathrm{~F}$-FAZA. ${ }^{124} \mathrm{I}$ is a popular choice owing to its longer half-life. The distribution of ${ }^{131}$ I-IAZGP (200) is similar to that of pimonidazole, and has a similar CA-IX expression profile in colorectal cancer models. ${ }^{124}$ I-IAZGP (201) can be used to image liver tumors within $6 \mathrm{~h}$ (202); however, there are insufficient tumor-absorption studies that support the clinical role of ${ }^{124}$ I-IAZGP PET in patients with colorectal cancer and head and neck cancer. ${ }^{124}$ I-FIAU (203) can be used to evaluate the expression of HSV1-tkeGFP fusion gene that is associated with hypoxia. The area where ${ }^{125}$ I-IPOS accumulates is positively correlated with the HIF- $1 \alpha$-positive area (204). ${ }^{125} \mathrm{I}$ M75 specifically accumulates in colorectal cancer xenografts within $48 \mathrm{~h}$ of administration and delineates hypoxia by targeting CA-IX (205). However, several radioactive iodine isotopes have long half-lives. Although these isotopes play a unique role in radioimmunotherapy, their use as imaging agents should be carefully assessed.

\section{${ }^{99 m}$ T $\mathbf{c}$}

The ${ }^{99 \mathrm{~m}} \mathrm{Tc}$-labeled complex is one of the earliest nonnitroimidazole contrast agents used to determine hypoxia in cells. ${ }^{99 \mathrm{~m}}$ Tc-labeled 2-nitroimidazole was also developed, with BMS181321 being the first. However, these agents are unstable and lipophilic, which limits their application (206). Subsequently, other tracers were developed to overcome these shortcomings (207). By choosing different cores and ligands, the tracer was designed to exhibit different characteristics to optimize the selection. The $\left[{ }^{99 \mathrm{~m}} \mathrm{Tc}(\mathrm{CO})_{3}\left(\mathrm{H}_{2} \mathrm{O}\right)\right]^{+}$nucleus is well studied for the labeling of nitroimidazole compounds (208). Recently, more focus has been placed on the introduction of tumor-targeting moieties (e.g., RGD). The ${ }^{99} \mathrm{~m}$ Tc nitroimidazole complex is retained longer in hypoxic tumor cells.

\section{Others}

In addition to the radionuclides discussed above, several others have been used for hypoxic PET. For example, ${ }^{111} \mathrm{In}$ is a promising candidate for imaging hypoxic areas to study head and neck tumors (209), prostate cancer (210), and colorectal cancer (211). The nitroimidazole and gastrin-releasing peptide receptor (BB2R) conjugate was labeled with ${ }^{177} \mathrm{Lu}$ (212); the CA-IX antibody G250$\mathrm{F}\left(\mathrm{ab}^{\prime}\right) 2$ was labeled with ${ }^{89} \mathrm{Zr}$ (213) and some promising results were obtained. Several nuclides are used in radiotherapy although their imaging effects are unsatisfactory or there are many factors worthy of improvement; however, these studies could help develop new ideas and research methodologies.

\section{DISCUSSION AND CONCLUSIONS}

Assessing the relationship between tumor tissue and hypoxia has been a fascinating topic in cancer research for many years mainly due to its complex correlation with disease progression and treatment response. In clinical research, in addition to the use of oxygen electrodes for research, the use of exogenous probes such as FMISO/FAZA-PET, HX4, Cu-ATSM, and pimonidazole, as well as methods that target endogenous markers, such as CAIX and HIF-1, are the mainstay to determine hypoxia (214). This review summarizes the progress of radionuclide-labeled PET tracers in hypoxia imaging. Each agent has its advantages and disadvantages; thus, it can only be used in a relatively limited range. Although some tracers have demonstrated the feasibility of their use in PET imaging hypoxia in several tumor entities in a clinical setting, so far, a perfect tracer with all desirable characteristics of an ideal PET hypoxia tracer has not been obtained.

One of the most important challenges in a clinical setting is the reproducibility of hypoxia imaging. The definition of the hypoxic area during measurement, selection of hypoxianormoxia threshold, time variability of $\mathrm{PO}_{2}$ levels in tumors during continuous measurement, heterogeneity within and between tumors of the same patient, and factors such as receiving treatment affect the reproducibility of scanning (215).

Blood perfusion is one of the obstacles that limits the use of traditional hypoxia tracers in the tumor microenvironment. Insufficient perfusion limits the effective delivery of the tracer to tissues, affects tracer accumulation in normal or tumor tissues, and leads to poor imaging effects or contradictory findings. Therefore, the special relationship between perfusion and hypoxia requires further clinical research for the evaluation of hypoxia-perfusion patterns in different tumor types as well as to elucidate their relationship with clinical outcomes. With the recent advent of PET-MRI scanners, multiple imaging models and multifunctional tools that provide perfusion information and increase the accuracy of hypoxia measurement and provide complementary information with higher predictive values will soon become possible.

Many problems need to be solved urgently to obtain the ideal and perfect tracer. Defining a relatively standardized hypoxia threshold or observation index, comparing various tracers to study different tumor types, and screening a more optimized imaging plan may be suitable approaches to achieve this goal.

In recent years, the research and application of nanotechnology in tumors has resulted in a very valuable tool, which aims to provide various possible solutions to address the shortcomings of current imaging agents. Nanocarriers have better permeability and retention in solid tumor tissues; thus, they can promote molecular delivery to overcome the poor vascular system in tumor tissues. Nanocarriers can also be used to carry materials with different targeting properties, or can be used in imaging systems with multiple modes to improve their biocompatibility (by reducing cytotoxicity) and add other functions to improve the accuracy and utility of the tracer (216).

Owing to the increasing clinical demand for the assessment of hypoxia, imaging for tumor hypoxia is of great significance for tumor diagnosis, prognosis assessment, and planning treatment strategies. Due to hypoxia-induced malignant progression of tumor cells and their resistance to radiotherapy and chemotherapy, several ongoing clinical trials are focusing on adjusting the radiotherapy regimen according to the degree of oxygenation of the tumor and assessing the benefits. 
Simultaneously, radiosensitizers and hypoxia activation studies in medicine are also underway. Thus, the goal of researchers who are studying hypoxia is to change clinical outcomes rather than just provide prognostic information.

\section{REFERENCES}

1. Pries AR, Cornelissen AJ, Sloot AA, Hinkeldey M, Dreher MR, Höpfner M, et al. Structural Adaptation and Heterogeneity of Normal and Tumor Microvascular Networks. PloS Comput Biol (2009) 5(5):e1000394. doi: 10.1371/journal.pcbi.1000394

2. Papp-Szabó E, Josephy PD, Coomber BL. Microenvironmental Influences on Mutagenesis in Mammary Epithelial Cells. Int J Cancer (2005) 116 (5):679-85. doi: 10.1002/ijc.21088

3. Carmeliet P, Jain RK. Angiogenesis in Cancer and Other Diseases. Nature (2000) 407(6801):249-57. doi: 10.1038/35025220

4. Ke Q, Costa M. Hypoxia-Inducible Factor-1 (HIF-1). Mol Pharmacol (2006) 70(5):1469-80. doi: 10.1124/mol.106.027029

5. Brahimi-Horn C, Pouyssegur J. The Role of Hypoxia-Inducible Factor in Tumor Metabolism Growth and Invasion. Bull Cancer (2006) 93(8):E73-80.

6. Semenza GL. Targeting HIF-1 for Cancer Therapy. Nat Rev Cancer (2003) 3 (10):721-32. doi: 10.1038/nrc1187

7. Pouyssé gur J, Dayan F, Mazure NM. Hypoxia Signalling in Cancer and Approaches to Enforce Tumour Regression. Nature (2006) 441(7092):437443. doi: $10.1038 /$ nature 04871

8. Goda N, Ryan HE, Khadivi B, McNulty W, Rickert RC, Johnson RS. Hypoxia- Inducible Factor 1alpha Is Essential for Cell Cycle Arrest During Hypoxia. Mol Cell Biol (2003) 23(1):359- 369. doi: 10.1128/ MCB.23.1.359-369.2003

9. Suzuki H, Tomida A, Tsuruo T. Dephosphorylated Hypoxia- Inducible Factor 1alpha as a Mediator of P53- Dependent Apoptosis During Hypoxia [J]. Oncogene (2001) 20(41):5779- 5788. doi: 10.1038/sj.onc.1204742

10. Safran M, Kealin W. HIF Hydroxylation and the Mammalian OxygenSensing Pathway. J Clin Invest (2003) 111(6):34-44. doi: 10.1172/JCI18181

11. Ferrara N, Gerber HP. LeCouter J.The Biology of VEGF and Its Receptors. Nat Med (2003) 9(6):669-76. doi: 10.1038/nm0603-669

12. Huang Y, Shi H, Zhou H, Song X, Yuan SP, Luo Y. The Angiogenic Function of Nucleolin Is Mediated by Vascular Endothelial Growth Factor and Nonmuscle Myosin. Blood (2006) 107(9):3564- 3571. doi: 10.1182/blood2005-07-2961

13. Carmeliet PV, Breier S, Ferreira G, Pollefeyt S, Kieckens L, Gertsenstein M, et al. Abnormal Blood Vessel Development and Lethality in Embryos Lacking a Single VEGF Allele. Nature (1996) 380(6573):435-9. doi: $10.1038 / 380435 \mathrm{a} 0$

14. Bergers G, Benjamin LE. Tumorigenesis and the Angiogenic Switch. Nat Rev Cancer (2003) 3(6):401- 410. doi: 10.1038/nrc1093

15. Busk M, Overgaard J, Horsman MR. Imaging of Tumor Hypoxia for Radiotherapy: Current Status and Future Directions. Semin Nucl Med (2020) 50(6):562-83. doi: 10.1053/j.semnuclmed.2020.05.003

16. Pastorek J, Pastorekova S. Hypoxia-Induced Carbonic Anhydrase IX as a Target for Cancer Therapy: From Biology to Clinical Use. Semin Cancer Biol (2015) 31:52-64. doi: 10.1016/j.semcancer.2014.08.002

17. Pastoreková S, Parkkila S, Parkkila AK, Opavský R, Zelník V, Saarnio J, et al. Carbonic Anhydrase IX, MN/CA IX: Analysis of Stomach Complementary DNA Sequence and Expression in Human and Rat Alimentary Tracts. Gastroenterology (1997) 112(2):398-408. doi: 10.1053/gast.1997.v112.pm9024293

18. Zavada J, Zavadova Z, Pastorek J, Biesova Z, Jezek K, Velek J. Human Tumour- Associated Cell Adhesion Protein MN/CA IX: Identification of M75 Epitope and of the Region Mediating Cell Adhesion. Br J Cancer (2000) 82:1808-13. doi: 10.1054/bjoc.2000.1111

19. Fukumura D, Jain RK. Tumor Microenvironment Abnormalities: Causes, Consequences, and Strategies to Normalize. J Cell Biochem (2007) 101 (4):937-49. doi: 10.1002/jcb.21187

20. Nelson DA, Tan TT, Rabson AB, Anderson D, Degenhardt K, White E. Hypoxia and Defective Apoptosis Drive Genomic Instability and

\section{AUTHOR CONTRIBUTIONS}

All authors listed have made a substantial, direct, and intellectual contribution to the work, and approved it for publication.

Tumorigenesis. Genes Dev (2004) 18(17):2095- 2107. doi: 10.1101/ gad.1204904

21. Horsman MR, Overgaard J. The Impact of Hypoxia and Its Modification of the Outcome of Radiotherapy. J Radiat Res (2016) 57(Suppl 1):90-i98. doi: 10.1093/jrr/rrw007

22. Horsman MR, Mortensen LS, Petersen JB, Busk M, Overgaard J. Imaging Hypoxia to Improve Radiotherapy Outcome. Nat Rev Clin Oncol (2012) 9 (12):674-87. doi: 10.1038/nrclinonc.2012.171

23. Qian BZ, Pollard JW. Macrophage Diversity Enhances Tumor Progression and Metastasis. Cell (2010) 141(1):39- 51. doi: 10.1016/j.cell.2010.03.014

24. Alberto M, Antonio S. Macrophages, Innate Immunity and Cancer: Balance, Tolerance, and Diversity. Curr Opin Immunol (2010) 22(2):231- 237. doi: 10.1016/j.coi.2010.01.009

25. Burke B, Tang N, Corke KP, Tazzyman D, Ameri K, Wells M, et al. Expression of HIF- $1 \alpha$ by Human Macrophages: Implications for the Use of Macrophages in Hypoxia- Regulated Cancer Gene Therapy. J Pathol (2002) 196(2):204- 212. doi: 10.1002/path.1029

26. Barker HE, Paget JT, Khan AA, Harrington KJ. The Tumour Microenvironment After Radiotherapy: Mechanisms of Resistance and Recurrence. Nat Rev Cancer (2015) 15(7):409-25. doi: 10.1038/nrc395878

27. Hockel M, Knoop C, Schlenger K, Vorndran B, Baussmann E, Mitze M, et al. Intratumoral Po2 Predicts Survival in Advanced Cancer of the Uterine Cervix. Radiother Oncol (1993) 26(1):45-5079. doi: 10.1016/0167-8140(93) 90025-4

28. Hockel M, Schlenger K, Knoop C, Vaupel P. Oxygena- Tion of Carcinomas of the Uterine Cervix: Evaluation by Com- Puterized O2 Tension Measurements. Cancer Res (1991) 51(22):6098-102. doi: 10.1038/nrc395878

29. Vaupel P, Schlenger K, Knoop C, Hockel M. Oxygena- Tion of Human Tumors: Evaluation of Tissue Oxygen Distribution in Breast Cancers by Computerized O2 Tension Measurements. Cancer Res (1991) 51(12):3316-22. doi: 10.1016/ 0167-8140(93)90025-4

30. Nordsmark M, Bentzen SM, Rudat V, Brizel D, Lartigau E, Stadler P, et al. Prognostic Value of Tumor Oxygenation in 397 Head and Neck Tumors After Primary Radiation Therapy. An International Multi-Center Study. Radiother Oncol (2005) 77(1):18-24. doi: 10.1016/j.radonc.2005.06.03882

31. Rudat V, Vanselow B, Wollensack P, Bettscheider C, Osman-Ahmet S, Eble MJ, et al. Repeatability and Prognostic Impact of the Pretreatment $\operatorname{Po}(2)$ Histography in Patients With Advanced Head and Neck Cancer. Radiother Oncol (2000) 57(1):31-7. doi: 10.1016/s0167-8140(00)00200-0

32. Bussink J, Kaanders JH, Strik AM, van der Kogel AJ. Effects of Nicotinamide and Carbogen on Oxygenation in Human Tumor Xenografts Measured With Luminescense Based Fiber-Optic Probes. Radiother Oncol (2000) 57 (1):21-30. doi: 10.1016/s0167-8140(00)00275-9

33. Gallez B, Baudelet C, Jordan BF. Assessment of Tumor Oxygenation by Electron Paramagnetic Resonance: Principles and Applications. NMR BioMed (2004) 17(5):240-62. doi: 10.1002/nbm.900

34. Okajo A, Ui I, Manda S, Nakanishi I, Matsumoto K-I, Anzai K, et al. Intracellular and Extracellular Redox Environments Surrounding RedoxSensitive Contrast Agents Under Oxidative Atmosphere. Biol Pharm Bull (2009) 32(4):535-41. doi: 10.1248/bpb.32.535

35. Hyodo F, Chuang K-H, Goloshevsky AG, Sulima A, Griffiths GL, Mitchell $\mathrm{JB}$, et al. Brain Redox Imaging Using Blood-Brain Barrier- Permeable Nitroxide MRI Contrast Agent. J Cereb Blood Flow Metab (2008) 28 (6):1165-74. doi: 10.1038/jcbfm.2008.5

36. Zhang Z, Hallac RR, Peschke P, Mason RP. A Noninvasive Tumor Oxygenation Imaging Strategy Using Magnetic Resonance Imaging of Endogenous Blood and Tis- Sue Water. Magn Reson Med (2014) 71 (2):561-9. doi: 10.1002/mrm.24691

37. Deng ZL, Wang Z, Yang XQ, Luo QM, Gong H. In Vivo Imaging of Hemodynamics and Oxygen Metabolism in Acute Focal Cerebral Ischemic 
Rats With Laser Speckle Im- Aging and Functional Photoacoustic Microscopy. J Biomed Opt (2012) 17(8):0814151-0814159. doi: 10.1117/ 1.JBO.17.8.081415

38. Wedegärtner U, Kooijman H, Andreas T, Beindorff N, Hecher K, Adam G. $\mathrm{T} 2$ and $\mathrm{T}^{*}$ Measurements of Fetal Brain Oxygenation During Hypoxia With MRI at 3T: Correla- Tion With Fetal Arterial Blood Oxygen Saturation. Eur Radiol (2010) 20(1):121-7. doi: 10.1007/s00330-009-1513-4

39. Kim SG, Ogawa S. Biophysical and Physiological Origins of Blood Oxygenation Level-Dependent fMRI Signals. J Cereb Blood Flow Metab (2012) 32(7):1188-206. doi: 10.1038/jcbfm.2012.23

40. Gross S, Gilead A, Scherz A, Neeman M, Salomon Y. Monitoring Photodynamic Therapy of Solid Tumors Online by BOLD-Contrast MRI. Nat Med (2003) 9(10):1327-31. doi: 10.1038/nm940

41. Tirotta I, Dichiarante V, Pigliacelli C, Cavallo C, Terraneo G, Bombelli FB, et al. (19)F Magnetic Resonance Imaging (MRI): From Design of Materials to Clinical Applications. Chem Rev (2015) 115(2):1106-29. doi: 10.1021/ cr500286d

42. Rojas-Quijano FA, Tircsó G, Tircsóné Benyó E, Baranyai Z, Hoang HT, Kálmán FK, et al. Synthesis and Characterization of a Hypoxia-Sensitive MRI Probe. Chemistry (2012) 18(31):9669-76. doi: 10.1002/ chem. 201200266

43. Martinelli J, Fekete M, Tei L, Botta M. Cleavable $\beta$ - Cyclodextrin Nanocapsules Incorporating Gd III-Chelates as Bioresponsive MRI Probes. Commun (2011) 47(11):3144-6. doi: 10.1039/c0cc05428c

44. Tsitovich PB, Spernyak JA, Morrow JR. A Redox-Activated MRI Contrast Agent That Switches Between Paramagnetic and Diamagnetic States. Angew Chem Int Ed Engl (2013) 52(52):13997-4000. doi: 10.1002/ anie. 201306394

45. Li Z, Chu T. Recent Advances on Radionuclide Labeled Hypoxia-Imaging Agents. Curr Pharm Des (2012) 18(8):1084-97. doi: 10.2174/ 138161212799315849

46. Mees G, Dierckx R, Vangestel C, Van de Wiele C. Molecular Imaging of Hypoxia With Radiolabelled Agents. Eur J Nucl Med Mol Imaging (2009) 36 (10):1674-86. doi: 10.1007/s00259-009-1195-9

47. Apte S, Chin FT, Graves EE. Molecular Imaging of Hypoxia: Strategies for Probe Design and Application. Curr Org Synth (2011) 8(4):593-603. doi: 10.2174/157017911796117179

48. Bayly SR, King RC, Honess DJ, Barnard PJ, Betts HM, Holland JP, et al. In Vitro and In Vivo Evaluations of a Hydrophilic 64Cu-Bis (Thiosemicarbazonato)-Glucose Conjugate for Hypoxia Imaging. $J$ Nucl Med (2008) 49(11):1862-8. doi: 10.2967/jnumed.108.054015

49. Mees G, Dierckx R, Vangestel C, Van de Wiele C. Molecular Imaging of Hypoxia With Radiolabelled Agents, Eur. J Nucl Med Mol Imaging (2009) 36 (10):1674-86. doi: 10.1007/s00259-009-1195-9

50. Bayer C, Shi K, Astner ST, Maftei C-A, Vaupel P. Acute Versus Chronic Hypoxia: Why a Simplified Classification is Simply Not Enough. Int J Radiat Oncol Biol Phys (2011) 80:965-8. doi: 10.1016/j.ijrobp.2011.02.049

51. Span PN, Bussink J. Biology of Hypoxia. Semin Nucl Med (2015) 45:101-9. doi: 10.1053/j.semnuclmed.2014.10.002

52. Chapman JD, Franko AJ, Sharplin J. A Marker for Hypoxic Cells in Tumours With Potential Clinical Applicability. Br J Cancer (1981) 43 (4):546-50. doi: 10.1038/bjc.1981.79

53. Chia K, Fleming IN, Blower PJ. Hypoxia Imaging With PET: Which Tracers and Why? Nucl Med Commun (2012) 33(3):217-22. doi: 10.1097/ MNM.0b013e32834eacb7

54. Rasey JS, Grunbaum Z, Krohn K, Nelson N, Chin L. Comparison of Binding of [3H]Misonidazole and [14C]Misonidazole in Multicell Spheroids. Radiat Res (1985) 101(3):473-9. doi: 10.2307/3576506

55. Chapman JD. Hypoxic Sensitisers - Implications for Radiation Therapy. N Engl J Med (1979) 301(26):1429-32. doi: 10.1056/NEJM 197912273012606

56. Wiebe LI, McEwan AJB. Scintigraphic Imaging of Focal Hypoxic Tissue: Development and Clinical Applications of 123I-IAZA. Braz Arch Biol Technol (2002) 45(Spec. Issue):69-81. doi: 10.1590/S1516-89132002000500010

57. Lee ST, Scott AM. Hypoxia Positron Emission Tomogra- Phy Imaging With 18f-Fluoromisonidazole. Semin Nucl Med (2007) 37(6):451-61. doi: 10.1053/ j.semnuclmed.2007.07.001
58. Aboagye EO, Lewis AD, Tracy M, Workman P. Bioreductive Metabolism of the Novel Fluorinated 2-Nitroimidazole Hypoxia Probe N-(2-Hydroxy3,3,3-Trifluoropropyl)-2-(2-Ni- Troimidazolyl) Acetamide (SR-4554). (1997) 54(11):1217-24. doi: 10.1016/s0006-2952(97)00344-4

59. Hunter FW, Young RJ, Shalev Z, Vellanki RN, Wang J, Gu Y, et al. Identification of P450 Oxidoreductase as a Major Determinant of Sensitivity to Hypoxia-Activated Prodrugs. Cancer Res (2015) 75 (19):4211-23. doi: 10.1158/0008-5472.CAN-15-1107

60. Masaki Y, Shimizu Y, Yoshioka T, Nishijima KI, Zhao S, Higashino K, et al. FMISO Accumulation in Tumor Is Dependent on Glutathione Conjugation Capacity in Addition to Hypoxic State. Ann Nucl Med (2017) 31(8):596-604. doi: 10.1007/s12149-017-1189-9

61. Shimizu Y. Accumulation Mechanism of 2-Nitroimidazole-Based Hypoxia Imaging Probes Revealed by Imaging Mass Spectrometry. Yakugaku Zasshi (2018) 138(11):1345-52. doi: 10.1248/yakushi.18-00146 Japanese.

62. Shimizu $\mathrm{Y}$, Nakai $\mathrm{Y}$, Watanabe H, Iikuni S, Ono M, Saji H, et al. Increased [18f]FMISO Accumulation Under Hypoxia by Multidrug-Resistant Protein 1 Inhibitors. EJNMMI Res (2021) 11(1):9. doi: 10.1186/s13550-021-00752-3

63. Krohn KA, Link JM, Mason RP. Molecular Imaging of Hypoxia. J Nucl Med (2008) 49(Suppl 2):129S-48S. doi: 10.2967/jnumed.107.045914

64. Lee ST, Scott AM. Hypoxia Positron Emission Tomogra- Phy Imaging With 18f-Fluoromisonidazole. Semin Nucl Med (2007) 37(6):451-61. doi: 10.1053/ j.semnuclmed.2007.07.001

65. Grierson JR, Link JM, Mathis CA, Rasey JS, Krohn KA. A Radiosynthesis of Fluorine-18 Fluoromisonidazole. J Nucl Med (1989) 30(3):343-50.

66. Bekaert L, Valable S, Lechapt-Zalcman E, Ponte K, Collet S, Constans JM, et al. [18f]-FMISO PET Study of Hypoxia in Gliomas Before Surgery: Correlation With Molecular Markers of Hypoxia and Angiogenesis. Eur J Nucl Med Mol Imaging (2017) 44(8):1383-92. doi: 10.1007/s00259-017$3677-5$

67. Cheng J, Lei L, Xu J, Sun Y, Zhang Y, Wang X, et al. 18F-Fluoromisonidazole PET/CT: A Potential Tool for Predicting Primary Endocrine Therapy Resistance in Breast Cancer. J Nucl Med (2013) 54(3):333-40. doi: $10.2967 /$ jnumed.112.111963

68. Löck S, Linge A, Seidlitz A, Bandurska-Luque A, Nowak A, Gudziol V, et al. Repeat FMISO-PET Imaging Weakly Correlates With Hypoxia-Associated Gene Expressions for Locally Advanced HNSCC Treated by Primary Radiochemotherapy. Radiother Oncol (2019) 135:43-50. doi: 10.1016/ j.radonc.2019.02.020

69. Thorwarth D, Welz S, Mönnich D, Pfannenberg C, Nikolaou K, Reimold M, et al. Prospective Evaluation of a Tumor Control Probability Model Based on Dynamic 18f-FMISO PET for Head and Neck Cancer Radiotherapy. J Nucl Med (2019) 60(12):1698-704. doi: 10.2967/jnumed.119.227744

70. Watanabe S, Inoue T, Okamoto S, Magota K, Takayanagi A, SakakibaraKonishi J, et al. Combination of FDG-PET and FMISO-PET as a Treatment Strategy for Patients Undergoing Early-Stage NSCLC Stereotactic Radiotherapy. EJNMMI Res (2019) 9(1):104. doi: 10.1186/s13550-0190578-6

71. Vavere AL, Lewis JS. Cu-ATSM: A Radiopharmaceutical for the PET Imaging of Hypoxia. Dalton Trans (2007) 43):4893-902. doi: 10.1039/ b705989b

72. Troost EGC, Laverman P, Philippens MEP, Lok J, Kogel AJ, Oyen WJG, et al. Correlation of [18F]FMISO Autoradiography and Pimonodazole Immunohistochemistry in Human Head and Neck Carcinoma Xenografts, Eur. J Nucl Med Mol Imaging (2008) 35(10):1803-11. doi: 10.1007/s00259008-0772-7

73. Postema EJ, McEwan AJ, Riauka TA, Kumar P, Richmond DA, Abrams DN, et al. Initial Results of Hypoxia Imaging Using 1-Alpha-D: -(5-Deoxy-5[18F]-Fluoroarabinofuranosyl)-2- Nitroimidazole (18F-FAZA). Eur J Nucl Med Mol Imaging (2009) 36(10):1565-73. doi: 10.1007/s00259-009-1154-5

74. Bollineni VR, Kerner GS, Pruim J, Steenbakkers RJ, Wiegman EM, Koole MJ, et al. PET Imaging of Tumor Hypoxia Using 18F-Fluoroazomycin Arabinoside in Stage III-IV Non-Small Cell Lung Cancer Patients. J Nucl Med (2013) 54(8):1175-80. doi: 10.2967/jnumed.112.115014

75. Trinkaus ME, Blum R, Rischin D, Callahan J, Bressel M, Segard T, et al. Imaging of Hypoxia With 18F-FAZA PET in Patients With Locally Advanced Non-Small Cell Lung Cancer Treated With Definitive 
Chemoradiotherapy. J Med Imaging Radiat Oncol (2013) 57(4):475-81. doi: $10.1111 / 1754-9485.12086$

76. Mortensen LS, Johansen J, Kallehauge J, Primdahl H, Busk M, Lassen P, et al. FAZA PET/CT Hypoxia Imaging in Patients With Squamous Cell Carcinoma of the Head and Neck Treated With Radiotherapy: Results From the DAHANCA 24 Trial. Radiother Oncol (2012) 105(1):14-20. doi: 10.1016/j.radonc.2012.09.015

77. Graves EE, Hicks RJ, Binns D, Bressel M, Le QT, Peters L, et al. Quantitative and Qualitative Analysis of [(18)F]FDG and [(18)F]FAZA Positron Emission Tomography of Head and Neck Cancers and Associations With HPV Status and Treatment Outcome. Eur J Nucl Med Mol Imaging (2016) 43 (4):617-25. doi: 10.1007/s00259-015-3247-7

78. Schuetz M, Schmid MP, Potter R, Kommata S, Georg D, Lukic D, et al. Evaluating Repetitive 18F-Fluoroazomycin-Arabinoside (18FAZA) PET in the Setting of MRI Guided Adaptive Radiotherapy in Cervical Cancer. Acta Oncol (2010) 49(7):941-7. doi: 10.3109/0284186X.2010.510145

79. Han K, Shek T, Vines D, Driscoll B, Fyles A, Jaffray D, et al. Measurement of Tumor Hypoxia in Patients With Locally Advanced Cervical Cancer Using Positron Emission Tomography With 18F-Fluoroazomyin Arabinoside. Int $J$ Radiat Oncol Biol Phys (2018) 102(4):1202-9. doi: 10.1016/ j.ijrobp.2018.02.030

80. Peeters SG, Zegers CM, Lieuwes NG, van Elmpt W, Eriksson J, van Dongen GA, et al. A Comparative Study of the Hypoxia PET Tracers $\left[{ }^{18} \mathrm{~F}\right] \mathrm{HX} 4,\left[{ }^{18} \mathrm{~F}\right]$ FAZA, and $\left[{ }^{18} \mathrm{~F}\right] \mathrm{FMISO}$ in a Preclinical Tumor Model. Int J Radiat Oncol Biol Phys (2015) 91(2):351-9. doi: 10.1016/j.ijrobp.2014.09.045

81. Havelund BM, Holdgaard PC, Rafaelsen SR, Mortensen LS, Theil J, Bender D, et al. Tumour Hypoxia Imaging With 18F-FluoroazomycinarabinofuRanoside PET/CT in Patients With Locally Advanced Rectal can- Cer. Nucl Med Commun (2013) 34(2):155-61. doi: 10.1097/MNM.0b013e $32835 \mathrm{bd} 5 \mathrm{bc}$

82. Lehtio K, Oikonen V, Gronroos T, Eskola O, Kalliokoski K, Bergman J, et al. Imaging of Blood Flow and Hypoxia in Head and Neck Cancer: Initial Evaluation With [15O]H2O and [18F] Fluoroerythronitroimidazole PET. $J$ Nucl Med (2001) 42:1643-52.

83. Yue J, Yang Y, Cabrera AR, Sun X, Zhao S, Xie P, et al. Measuring Tumor Hypoxia With ${ }^{18}$ F-FETNIM PET in Esophageal Squamous Cell Carcinoma: A Pilot Clinical Study. Dis Esophagus (2012) 25(1):54-61. doi: 10.1111/j.14422050.2011.01209.x

84. Lehtio K, Oikonen V, Nyman S, Grönroos T, Roivainen A, Eskola O, et al. Quantifying Tumour Hypoxia With Fluorine-18 Fluoroerythronitroimidazole ([18F]FETNIM) and PET Using the Tumour to Plasma Ratio. Eur J Nucl Med Mol Imaging (2003) 30(1):101-8. doi: $10.1007 / \mathrm{s} 00259-002-1016-x$

85. Lehtio K, Eskola O, Viljanen T, Oikonen V, Grönroos T, Sillanmäki L, et al. Imaging Perfusion and Hypoxia With PET to Predict Radiotherapy Response in Head-and- Neck Cancer. Int J Radiat Oncol Biol Phys (2004) 59(4):971-82. doi: 10.1016/j.ijrobp.2003.12.014

86. Hu M, Xie P, Lee NY, Li M, Ho F, Lian M, et al. Hypoxia With 18FFluoroerythronitroimidazole Integrated Positron Emission Tomography and Computed Tomography (18F-FETNIM PET/CT) in Locoregionally Advanced Head and Neck Cancer: Hypoxia Changes During Chemoradiotherapy and Impact on Clinical Outcome. Med (Baltimore) (2019) 98(40):e17067. doi: 10.1097/MD.0000000000017067

87. Vercellino L, Groheux D, Thoury A, Delord M, Schlageter MH, Delpech Y, et al. Hypoxia Imaging of Uterine Cervix Carcinoma With (18)F-FETNIM PET/Ct. Clin Nucl Med (2012) 37(11):1065-8. doi: 10.1097/ RLU.0b013e3182638e7e

88. Li L, Hu M, Zhu H, Zhao W, Yang G, Yu J. Comparison of $18 \mathrm{~F}-$ Fluoroerythronitroimidazole And18f-Fluorodeoxyglucose Positron Emission Tomography and Prognostic Value in Locally Advanced NonSmall- Cell Lung Cancer. Clin Lung Cancer (2010) 11(5):335-40. doi: 10.3816/CLC.2010.n.042

89. Hu M, Xing L, Mu D, Yang W, Yang G, Kong L, et al. Hypoxia Imaging With18f-Fluoroerythronitroimidazole Integrated PET/CT and Immunohistochemical Studies in Non-Small Cell Lung Cancer. Clin Nucl Med (2013) 38(8):591-6. doi: 10.1097/RLU.0b013e318279fd3d

90. Wei Y, Zhao W, Huang Y, Yu Q, Zhu S, Wang S, et al. A Comparative Study of Noninvasive Hypoxia Imaging With 18F-Fluoroerythronitroimidazole and 18F-Fluoromisonidazole PET/CT in Patients With Lung Cancer. PloS One (2016) 11(6):e0157606. doi: 10.1371/journal.pone.0157606

91. Beppu T, Terasaki K, Sasaki T, Fujiwara S, Matsuura H, Ogasawara K, et al. Standardized Uptake Value in High Uptake Area on Positron Emission Tomography With 18F-FRP170 as a Hypoxic Cell Tracer Correlates With Intratumoral Oxygen Pressure in Glioblastoma. Mol Imaging Biol (2014) 16 (1):127-35. doi: 10.1007/s11307-013-0670-7

92. Beppu T, Sasaki T, Terasaki K, Saura H, Mtsuura H, Ogasawara K, et al. High-Uptake Areas on Positron Emission Tomography With the Hypoxic Radiotracer (18)F-FRP170 in Glioblastomas Include Regions Retaining Proliferative Activity Under Hypoxia. Ann Nucl Med (2015) 29(4):336-41. doi: 10.1007/s12149-015-0951-0

93. Shibahara I, Kumabe T, Kanamori M, Saito R, Sonoda Y, Watanabe M, et al. Imaging of Hypoxic Lesions in Patients With Gliomas by Using Positron Emission Tomography With 1-(2-[18F] Fluoro-1[Hydroxymethyl]Ethoxy)Methyl-2-Nitroimidazole, A New 18F-Labeled 2Nitroimidazole Analog. J Neurosurg (2010) 113(2):358-68. doi: 10.3171/ 2009.10.JNS09510

94. Kaneta T, Takai Y, Iwata R, Hakamatsuka T, Yasuda H, Nakayama K, et al. Initial Evaluation of Dynamic Human Imaging Using 18F-FRP170 as a New PET Tracer for Imaging Hypoxia. Ann Nucl Med (2007) 21(2):101-7. doi: $10.1007 / \mathrm{BF} 03033987$

95. Koch CJ, Scheuermann JS, Divgi C, Judy KD, Kachur AV, Freifelder R, et al. Biodistribution and Dosimetry Of18f-EF5 in Cancer Patients With Preliminary Comparison Of18f-EF5 Uptake Versus EF5 Binding in Human Glioblastoma. Eur J Nucl Med Mol Imaging (2010) 37:2048-59. doi: 10.1007/s00259-010-1517-y

96. Komar G, Seppänen M, Eskola O, Lindholm P, Grönroos TJ, Forsback S, et al. 18f-EF5: A New PET Tracer for Imaging Hypoxia in Head and Neck Cancer. J Nucl Med (2008) 49(12):1944-51. doi: 10.2967/jnumed.108.053785

97. Ali R, Apte S, Vilalta M, Subbarayan M, Miao Z, Chin FT, et al. 18f-EF5 PET Is Predictive of Response to Fractionated Radiotherapy in Preclinical Tumor Models. PloS One (2015) 10(10):e0139425. doi: 10.1371/ journal.pone. 0139425

98. Dubois LJ, Lieuwes NG, Janssen MH, Peeters WJ, Windhorst AD, Walsh JC, et al. Preclinical Evaluation and Validation of [18F]HX4, A Promising Hypoxia Marker for PET Imaging. Proc Natl Acad Sci USA (2011) 108 (35):14620-5. doi: 10.1073/pnas.1102526108

99. Doss M, Zhang JJ, Bélanger MJ, Stubbs JB, Hostetler ED, Alpaugh K, et al. Biodistribution and Radiation Dosimetry of the Hypoxia Marker 18F-HX4 in Monkeys and Humans Determined by Using Whole-Body PET/Ct. Nucl Med Commun (2010) 31(12):1016-24. doi: 10.1097/MNM.0b013e 3283407950

100. Peeters SG, Zegers CM, Lieuwes NG, van Elmpt W, Eriksson J, van Dongen GA, et al. A Comparative Study of the Hypoxia PET Tracers $\left[{ }^{18} \mathrm{~F}\right] \mathrm{HX} 4,\left[{ }^{18} \mathrm{~F}\right]$ FAZA, and $\left[{ }^{18} \mathrm{~F}\right] \mathrm{FMISO}$ in a Preclinical Tumor Model. Int J Radiat Oncol Biol Phys (2015) 91(2):351-9. doi: 10.1016/j.ijrobp.2014.09.045

101. Carlin S, Zhang H, Reese M, Ramos NN, Chen Q, Ricketts SA. A Comparison of the Imaging Characteristics and Microregional Distribution of 4 Hypoxia PET Tracers. J Nucl Med (2014) 55(3):515-21. doi: 10.2967/jnumed.113.126615

102. Zegers CM, van Elmpt W, Reymen B, Even AJ, Troost EG, Ollers MC, et al. In Vivo Quantification of Hypoxic and Metabolic Status of NSCLC Tumors Using [18F]HX4 and [18F]FDG-PET/CT Imaging. Clin Cancer Res (2014) 20(24):6389-97. doi: 10.1158/1078-0432.CCR-14-1524

103. Chen L, Zhang Z, Kolb HC, Walsh JC, Zhang J, Guan Y. ${ }^{18} \mathrm{~F}-\mathrm{HX} 4$ Hypoxia Imaging With PET/CT in Head and Neck Cancer: A Comparison With ${ }^{18}$ F-FMISO. Nucl Med Commun (2012) 33(10):1096-102. doi: 10.1097/ MNM.0b013e3283571016

104. Zegers CM, Hoebers FJ, van Elmpt W, HoBonsebers JA, Öllers MC, Troost EG, et al. Evaluation of Tumour Hypoxia During Radiotherapy Using [18F] HX4 PET Imaging and Blood Biomarkers in Patients With Head and Neck Cancer. Eur J Nucl Med Mol Imaging (2016) 43(12):2139-46. doi: 10.1007/ s00259-016-3429-y

105. Klaassen R, Bennink RJ, van Tienhoven G, Bijlsma MF, Besselink MG, van Berge Henegouwen MI, et al. Feasibility and Repeatability of PET With the Hypoxia Tracer [(18)F]HX4 in Oesophageal and Pancreatic Cancer. Radiother Oncol (2015) 116(1):94-9. doi: 10.1016/j.radonc.2015.05.009 
106. Zegers CM, van Elmpt W, Szardenings K, Kolb H, Waxman A, Subramaniam RM, et al. Repeatability of Hypoxia PET Imaging Using $\left[{ }^{18} \mathrm{~F}\right] \mathrm{HX} 4$ in Lung and Head and Neck Cancer Patients: A Prospective Multicenter Trial. Eur J Nucl Med Mol Imaging (2015) 42(12):1840-9. doi: $10.1007 / \mathrm{s} 00259-015-3100-z$

107. Fujibayashi Y, Taniuchi H, Yonekura Y, Ohtani H, Konishi J, Yokoyama A. Copper-62-ATSM: A New Hypoxia Imaging Agent With High Membrane Permeability and Low Redox Potential. J Nucl Med (1997) 38:1155-60.

108. Holland JP, Lewis JS, Dehdashti F. Assessing Tumor Hypoxia by Positron Emission Tomography With Cu-ATSM. Q J Nucl Med Mol Imaging (2009) 53:193-200.

109. Lewis JS, McCarthy DW, McCarthy TJ, Fujibayashi Y, Welch MJ. Evaluation of 64Cu-ATSM In Vitro and In Vivo in a Hypoxic Tumor Model, J. Nucl Med (1999) 40(1):177-83.

110. Takahashi N, Fujibayashi Y, Yonekura Y, Welch MJ, Waki A, Tsuchida T, et al. Evaluation of 62Cu Labeled Diacetyl-Bis(N4-Methylthiosemicarbazone) as a Hypoxic Tissue Tracer in Patients With Lung Cancer. Ann Nucl Med (2000) 14(5):323-8. doi: 10.1007/BF02988690

111. Dehdashti F, Grigsby PW, Mintun MA, Lewis JS, Siegel BA, Welch MJ. Assessing Tumor Hypoxia in Cervical Cancer by Positron Emission Tomography With 60Cu-ATSM: Relationship to Therapeutic Response-a Preliminary Report. Int J Radiat Oncol Biol Phys (2003) 55(5):1233-8. doi: 10.1016/s0360-3016(02)04477-2

112. Dehdashti F, Mintun MA, Lewis JS, Bradley J, Govindan R, Laforest R, et al. In Vivo Assessment of Tumor Hypoxia in Lung Cancer With 60Cu-ATSM. Eur J Nucl Med Mol Imaging (2003) 30(6):844-50. doi: 10.1007/s00259-003$1130-4$

113. Obata A, Yoshimi E, Waki A, Lewis JS, Oyama N, Welch MJ, et al. Retention Mechanism of Hypoxia Selective Nuclear Imaging/ Radiotherapeutic Agent Cu-Diacetyl-Bis(N4-Methylthiosemicarbazone) (Cu-ATSM) in Tumor Cells. Ann Nucl Med (2001) 15(6):499-504. doi: $10.1007 / \mathrm{BF} 02988502$

114. Dearling JL, Packard AB. Some Thoughts on the Mechanism of Cellular Trapping of Cu(II)-ATSM. Nucl Med Biol (2010) 37(3):237-43. doi: 10.1016/ j.nucmedbio.2009.11.004

115. Hueting R, Kersemans V, Cornelissen B, Tredwell M, Hussien K, Christlieb $\mathrm{M}$, et al. A Comparison of the Behavior of (64)Cu-Acetate and (64)CuATSM In Vitro and In Vivo. J Nucl Med (2014) 55(1):128-34. doi: 10.2967/ jnumed.113.119917

116. Dearling JL, Lewis JS, Mullen GE, Welch MJ, Blower PJ. Copper Bis (Thiosemicarbazone) Complexes as Hypoxia Imaging Agents: StructureActivity Relationships. J Biol Inorg Chem (2002) 7(3):249-59. doi: 10.1007/ s007750100291

117. Holland JP, Barnard PJ, Collison D, Dilworth JR, Edge R, Green JC, et al. Spectroelectrochemical and Computational Studies on the Mechanism of Hypoxia Selectivity of Copper Radiopharmaceuticals. Chemistry (2008) 14 (19):5890-907. doi: 10.1002/chem.200800539

118. Kositwattanarerk A, Oh M, Kudo T, Kiyono Y, Mori T, Kimura Y, et al. Different Distribution of (62) Cu ATSM and (18)F-FDG in Head and Neck Cancers. Clin Nucl Med (2012) 37(3):252-7. doi: 10.1097/RLU. 0b013e31823eaadb

119. Lohith TG, Kudo T, Demura Y, Umeda Y, Kiyono Y, Fujibayashi Y, et al. Pathophysiologic Correlation Between 62Cu-ATSM and 18F-FDG in Lung Cancer. J Nucl Med (2009) 50(12):1948-53. doi: 10.2967/jnumed.109.069021

120. Capasso E, Durzu S, Piras S, Zandieh S, Knoll P, Haug A, et al. Role of (64) $\mathrm{CuCl} 2 \mathrm{PET} / \mathrm{CT}$ in Staging of Prostate Cancer. Ann Nucl Med (2015) 29 (6):482-8. doi: 10.1007/s12149-015-0968-4

121. Piccardo A, Paparo F, Puntoni M, Righi S, Bottoni G, Bacigalupo L, et al. 64cucl2 PET/CT in Prostate Cancer Relapse. J Nucl Med (2018) 59(3):44451. doi: $10.2967 /$ jnumed.117.195628

122. Johnson TE, Birky BK. Health Physics and Radiological Health. 4th ed. Philadelphia: Lippincott Williams \& Wilkins (2011).

123. Fleming IN, Manavaki R, Blower PJ, West C, Williams KJ, Harris AL, et al. Imaging Tumour Hypoxia With Positron Emission Tomography. $\mathrm{Br} J$ Cancer (2015) 112(2):238-50. doi: 10.1038/bjc.2014.610

124. Challapalli A, Carroll L, Aboagye E. Molecular Mechanisms of Hypoxia in Cancer. Clin Transl Imaging (2017) 5:225-53. doi: 10.1007/s40336-0170231-1
125. Dubois L, Landuyt W, Haustermans K, Dupont P, Bormans G, Vermaelen P, et al. Evaluation of Hypoxia in an Experimental Rat Tumour Model by [(18) F]fluoromisonidazole PET and Immunohistochemistry. Br J Cancer (2004) 91(11):1947-54. doi: 10.1038/sj.bjc.6602219

126. Dubois LJ, Lieuwes NG, Janssen MH, Peeters WJ, Windhorst AD, Walsh JC, et al. Preclinical Evaluation and Validation of $[18 \mathrm{~F}] \mathrm{HX} 4$, a Promising Hypoxia Marker for PET Imaging. Proc Natl Acad Sci USA (2011) 108 (35):14620-5. doi: 10.1073/pnas.1102526108

127. Carlin S, Zhang H, Reese M, Ramos NN, Chen Q, Ricketts S-A. A Comparison of the Imaging Characteristics and Microregional Distribution of 4 Hypoxia PET Tracers. J Nucl Med (2014) 55:515-21. doi: 10.2967/jnumed.113.126615

128. Yip C, Blower PJ, Goh V, Landau DB, Cook GJ. Molecular Imaging of Hypoxia in Non-Small-Cell Lung Cancer. Eur J Nucl Med Mol Imaging (2015) 42(6):956-76. doi: 10.1007/s00259-015-3009-6

129. Busk M, Horsman M, Jakobsen S, Bussink J, van der Kogel A, Overgaard J. Cellular Uptake of PET Tracers of Glucose Metabolism and Hypoxia and Their Linkage. Eur J Nucl Med Mol Imaging (2008) 35:2294-303. doi: 10.1007/s00259-008-0888-9

130. Lehtiö K, Oikonen V, Nyman S, Grönroos T, Roivainen A, Eskola O, et al. Quantifying Tumour Hypoxia With Fluorine-18 Fluoroerythronitroimidazole ([18F]FETNIM) and PET Using the Tumour to Plasma Ratio. Eur J Nucl Med Mol Imaging (2003) 30(1):101-8. doi: 10.1007/s00259-002-1016-x

131. Dolbier WR, Li A-R, Koch CJ, Shiue C-Y, Kachur AV. [18f]-EF5, a Marker for PET Detection of Hypoxia: Synthesis of Precursor and a New Fluorination Procedure. Appl Radiat Isot (2001) 54:73-80. doi: 10.1016/ s0969-8043(00)00102-0

132. Kaneta T, Takai $Y$, Iwata R, Hakamatsuka T, Yasuda H, Nakayama K, et al. Initial Evaluation of Dynamic Human Imaging Using 18F-FRP170 as a New PET Tracer for Imaging Hypoxia. Ann Nucl Med (2007) 21(2):101-7. doi: $10.1007 / \mathrm{BF} 03033987$

133. Rajendran JG, Krohn KA. F-18 Fluoromisonidazole for Imaging Tumor Hypoxia: Imaging the Microenvironment for Personalized Cancer Therapy. Semin Nucl Med (2015) 45:151-62. doi: 10.1053/j.semnuclmed.2014.10.006

134. Picchio M, Beck R, Haubner R, Seidl S, Machulla HJ, Johnson TD, et al. Intratumoral Spatial Distribution of Hypoxia and Angiogenesis Assessed by 18F-FAZA and 125I-Gluco-RGD Autoradiography. J Nucl Med (2008) 49 (4):597-605. doi: 10.2967/jnumed.107.046870

135. Lehtiö K, Oikonen V, Grönroos T, Eskola O, Kalliokoski K, Bergman J, et al. Imaging of Blood Flow and Hypoxia in Head and Neck Cancer: Initial Evaluation With [(15)O]H(2)O and [(18)F]fluoroerythronitroimidazole PET. J Nucl Med (2001) 42(11):1643-52. doi: 10.1038/bjc.2014.610

136. Reymen BJT, van Gisbergen MW, Even AJG, Zegers CML, Das M, Vegt E, et al. Nitroglycerin as a Radiosensitizer in Non-Small Cell Lung Cancer: Results of a Prospective Imaging-Based Phase II Trial. Clin Transl Radiat Oncol (2019) 21:49-55. doi: 10.1016/j.ctro.2019.12.002

137. Liu J, Hajibeigi A, Ren G, Lin M, Siyambalapitiyage W, Liu Z, et al. Retention of the Radiotracers 64Cu-ATSM and 64Cu-PTSM in Human and Murine Tumors Is Influenced by MDR1 Protein Expression. J Nucl Med (2009) 50 (8):1332-9. doi: 10.2967/jnumed.109.061879

138. Krohn KA, Link JM, Mason RP. Molecular Imaging of Hypoxia. J Nucl Med (2008) 49 Suppl 2:129S-48S. doi: 10.2967/jnumed.107.045914

139. Vavere AL, Lewis JS. Examining the Relationship Between Cu-ATSM Hypoxia Selectivity and Fatty Acid Synthase Expression in Human Prostate Cancer Cell Lines. Nucl Med Biol (2008) 35:273-9. doi: 10.1016/ j.nucmedbio.2007.11.012

140. Verwer E. Quantification and Clinical Applicability of Novel Oncology PET Imaging Biomarkers. Amsterdam, The Netherlands: Universitair Medische Centra (2015).

141. Peerlings J, Van De Voorde L, Mitea C, Larue R, Yaromina A, Sandeleanu S, et al. Hypoxia and Hypoxia Response-Associated Molecular Markers in Esophageal Cancer: A Systematic Review. Methods (2017) 130:51-62. doi: 10.1016/ j.ymeth.2017.07.002

142. McCall KC, Humm JL, Bartlett R, Reese M, Carlin S. Copper-64-Diacetyl-Bis(N (4)-Methylthiosemicarbazone) Pharmacokinetics in FaDu Xenograft Tumors and Correlation With Microscopic Markers of Hypoxia. Int J Radiat Oncol Biol Phys (2012) 84(3):e393-9. doi: 10.1016/j.jirobp.2012.05.005 
143. Ishikawa Y, Iwata R, Furumoto S, Takai Y. Automated Preparation of Hypoxic Cell Marker [18F]FRP-170 by on-Column Hydrolysis. Appl Radiat Isot (2005) 62(5):705-10. doi: 10.1016/j.apradiso.2004.09.008

144. Corrigan LL. PET Radiopharmaceuticals. In: Radiopharmacy: An Update. A Technologist's Guide. Vienna, Austria: European Association of Nuclear Medicine (2019). p. 96-101.

145. Koch CJ, Scheuermann JS, Divgi C, Judy KD, Kachur AV, Freifelder R, et al. Biodistribution and Dosimetry of (18)F-EF5 in Cancer Patients With Preliminary Comparison of (18)F-EF5 Uptake Versus EF5 Binding in Human Glioblastoma. Eur J Nucl Med Mol Imaging (2010) 37(11):204859. doi: 10.1007/s00259-010-1517-y

146. Grkovski M, Schwartz J, Rimner A, Schöder H, Carlin SD, Zanzonico PB, et al. Reproducibility of 18F-Fluoromisonidazole Intratumour Distribution in Non-Small Cell Lung Cancer. EJNMMI Res (2016) 6(1):79. doi: 10.1186/ s13550-016-0210-y

147. Busk M, Mortensen LS, Nordsmark M, Overgaard J, Jakobsen S, Hansen KV, et al. PET Hypoxia Imaging With FAZA: Reproducibility at Baseline and During Fractionated Radiotherapy in Tumour-Bearing Mice. Eur J Nucl Med Mol Imaging (2013) 40(2):186-97. doi: 10.1007/s00259-012-2258-x

148. Yue J, Yang Y, Cabrera AR, Sun X, Zhao S, Xie P, et al. Measuring Tumor Hypoxia With ${ }^{18}$ F-FETNIM PET in Esophageal Squamous Cell Carcinoma: A Pilot Clinical Study. Dis Esophagus (2012) 25(1):54-61. doi: 10.1111/ j.1442-2050.2011.01209.x

149. Silvoniemi A, Suilamo S, Laitinen T, Forsback S, Löyttyniemi E, Vaittinen S, et al. Repeatability of Tumour Hypoxia Imaging Using [18F]EF5 PET/CT in Head and Neck Cancer. Eur J Nucl Med Mol Imaging (2018) 45(2):161-9. doi: 10.1007/s00259-017-3857-3

150. Klaassen R, Bennink RJ, van Tienhoven G, Bijlsma MF, Besselink MG, van Berge Henegouwen MI, et al. Feasibility and Repeatability of PET With the Hypoxia Tracer [(18)F]HX4 in Oesophageal and Pancreatic Cancer. Radiother Oncol (2015) 116(1):94-9. doi: 10.1016/j.radonc.2015.05.009

151. Chitneni SK, Bida GT, Zalutsky MR, Dewhirst MW. Comparison of the Hypoxia PET Tracer (18)F-EF5 to Immunohistochemical Marker EF5 in 3 Different Human Tumor Xenograft Models. J Nucl Med (2014) 55(7):11927. doi: $10.2967 /$ jnumed.114.137448

152. Yuan H, Schroeder T, Bowsher JE, Hedlund LW, Wong T, Dewhirst MW. Intertumoral Differences in Hypoxia Selectivity of the PET Imaging Agent 64Cu(II)-Diacetyl-Bis(N4-Methylthiosemicarbazone). J Nucl Med (2006) 47:989-98.

153. Minagawa Y, Shizukuishi K, Koike I, Horiuchi C, Watanuki K, Hata M, et al. Assessment of Tumor Hypoxia by 62Cu-ATSM PET/CT as a Predictor of Response in Head and Neck Cancer: A Pilot Study. Ann Nucl Med (2011) 25 (5):339-45. doi: 10.1007/s12149-011-0471-5

154. Nyflot MJ, Harari PM, Yip S, Perlman SB, Jeraj R. Correlation of PET Images of Metabolism, Proliferation and Hypoxia to Characterize Tumor Phenotype in Patients With Cancer of the Oropharynx. Radiother Oncol (2012) 105 (1):36-40. doi: 10.1016/..radonc.2012.09.012

155. Takahashi N, Fujibayashi Y, Yonekura Y, Welch MJ, Waki A, Tsuchida T, et al. Evaluation of $62 \mathrm{Cu}$ Labeled Diacetyl-Bis(N4-Methylthiosemicarbazone) as a Hypoxic Tissue Tracer in Patients With Lung Cancer. Ann Nucl Med (2000) 14 (5):323-8. doi: 10.1007/BF02988690

156. Lohith TG, Kudo T, Demura Y, Umeda Y, Kiyono Y, Fujibayashi Y, et al. Pathophysiologic Correlation Between 62Cu-ATSM and 18F-FDG in Lung Cancer. J Nucl Med (2009) 50(12):1948-53. doi: 10.2967/jnumed.109.069021

157. Lewis JS, Laforest R, Dehdashti F, Grigsby PW, Welch MJ, Siegel BA. An Imaging Comparison Of64cu-ATSM And60cu-ATSM in Cancer of the Uterine Cervix. J Nucl Med (2008) 49(7):1177-82. doi: 10.2967/ jnumed.108.051326

158. Dehdashti F, Grigsby PW, Lewis JS, Laforest R, Siegel BA, Welch MJ. Assessing Tumor Hypoxia in Cervical Cancer by PET With60cu-Labeled Diacetyl-Bis(N4-methylthiosemicarbazone). J Nucl Med (2008) 49(2):2015. doi: 10.2967/jnumed.107.048520

159. Dietz DW, Dehdashti F, Grigsby PW, Malyapa RS, Myerson RJ, Picus J, et al. Tumor Hypoxia Detected by Positron Emission Tomography With 60Cu-ATSM as a Predictor of Response and Survival in Patients Undergoing Neoadjuvant Chemoradiotherapy for Rectal Carcinoma: A Pilot Study. Dis Colon Rectum (2008) 51(11):1641-8. doi: 10.1007/ s10350-008-9420-3
160. Tateishi K, Tateishi U, Sato M, Yamanaka S, Kanno H, Murata H, et al. Application of 62Cu-Diacetyl-Bis (N4-Methylthiosemicarbazone) PET Imaging to Predict Highly Malignant Tumor Grades and HypoxiaInducible Factor- $1 \alpha$ Expression in Patients With Glioma. AJNR Am J Neuroradiol (2013) 34(1):92-9. doi: 10.3174/ajnr.A3159

161. Minagawa Y, Shizukuishi K, Koike I, Horiuchi C, Watanuki K, Hata M, et al. Assessment of Tumor Hypoxia by 62Cu-ATSM PET/CT as a Predictor of Response in Head and Neck Cancer: A Pilot Study. Ann Nucl Med (2011) 25 (5):339-45. doi: 10.1007/s12149-011-0471-5

162. Panichelli P, Villano C, Cistaro A, Bruno A, Barbato F, Piccardo A, et al. Imaging of Brain Tumors With Copper-64 Chloride: Early Experience and Results. Cancer Biother Radiopharm (2016) 31(5):159-67. doi: 10.1089/ cbr.2016.2028

163. Lewis J, Laforest R, Buettner T, Song S-K, Fujibayashi TY, Connett JM, et al. Copper-64-Diacetyl-Bis(N4-Methylthiosemicarbazone): An Agent for Radiotherapy. Proc Natl Acad Sci USA (2001) 98(3):1206-11. doi: 10.1073/ pnas.98.3.1206

164. Obata A, Kasamatsu S, Lewis JS, Furukawa T, Takamatsu S, Toyohara J, et al. Basic Characterization of 64Cu-ATSM as a Radiotherapy Agent. Nucl Med Biol (2005) 32(1):21-8. doi: 10.1016/j.nucmedbio.2004.08.012 Erratum in: Nucl Med Biol. 2005;32(5):559.

165. Bruehlmeier M, Roelcke U, Schubiger PA, Ametamey SM. Assessment of Hypoxia and Perfusion in Human Brain Tumors Using PET With 18FFluoromisonidazole and 15O-H2O. J Nucl Med (2004) 45(11):1851-9.

166. Cher LM, Murone C, Lawrentschuk N, Ramdave S, Papenfuss A, Hannah A, et al. Correlation of Hypoxic Cell Fraction and Angiogenesis With Glucose Metabolic Rate in Gliomas Using 18F-Fluoromisonidazole, 18FFDG PET, and Immunohisto- Chemical Studies. J Nucl Med (2006) 47 (3):410-8

167. Swanson KR, Chakraborty G, Wang CH, Rockne R, Harpold HL, Muzi M, et al. Complementary But Distinct Roles for MRI and 18F-Fluoromisonidazole PET in the Assessment of Human Glioblastomas. J Nucl Med (2009) 50(1):36-44. doi: 10.2967/jnumed.108.055467

168. Abolmaali N, Haase R, Koch A, Zips D, Steinbach J, Baumann M, et al. Two or Four Hour [(1)(8)F]FMISO-PET in HNSCC. When Is the Contrast Best? Nuklearmedizin (2011) 50(1):22-7. doi: 10.3413/nukmed-00328-10-07

169. Sato J, Kitagawa Y, Yamazaki Y, Hata H, Okamoto S, Shiga T, et al. 18FFluoromisonidazole PET Uptake Is Correlated With Hypoxia-Inducible Factor-1alpha Expression in Oral Squamous Cell Carcinoma. J Nucl Med (2013) 54(7):1060-5. doi: 10.2967/jnumed.112.114355

170. Nehmeh SA, Lee NY, Schroder H, Squire O, Zanzonico PB, Erdi YE, et al. Reproducibility of Intratumor Distribution of (18)F-Fluoromisonidazole in Head and Neck Cancer. Int J Radiat Oncol Biol Phys (2008) 70(1):235-42. doi: 10.1016/ j.ijrobp.2007.08.036

171. Zips D, Zophel K, Abolmaali N, Perrin R, Abramyuk A, Haase R, et al. Exploratory Prospective Trial of Hypoxia-Specific PET Imaging During Radiochemotherapy in Patients With Locally Advanced Head-and-Neck Cancer. Radiother Oncol (2012) 105(1):21-8. doi: 10.1016/j.radonc.2012. 08.019

172. Tachibana I, Nishimura Y, Shibata T, Kanamori S, Nakamatsu K, Koike R, et al. A Prospective Clinical Trial of Tumor Hypoxia Imaging With 18FFluoromisonidazole Positron Emission Tomography and Computed Tomography (F-MISO PET/CT) Before and During Radiation Therapy. J Radiat Res (2013) 54(6):1078-84. doi: 10.1093/jrr/rrt033

173. Sato J, Kitagawa Y, Yamazaki Y, Hata H, Asaka T, Miyakoshi M, et al. Advantage of FMISO-PET Over FDG-PET for Predicting His- Tological Response to Preoperative Chemotherapy in Patients With Oral Squamous Cell Carcinoma. Eur J Nucl Med Mol Imaging (2014) 41(11):2031-41. doi: 10.1007/s00259-014-2810-y

174. Kikuchi M, Yamane T, Shinohara S, Fujiwara K, Hori SY, Tona Y, et al. 18FFluo- Romisonidazole Positron Emission Tomography Before Treatment Is a Predictor of Radiotherapy Outcome and Survival Prognosis in Patients With Head and Neck Squamous Cell Carcinoma. Ann Nucl Med (2011) 25(9):62533. doi: 10.1007/s12149-011-0508-9

175. Yamane T, Kikuchi M, Shinohara S, Senda M. Reduction of [(18)F] fluoromisonidazole Uptake After Neoadjuvant Chemotherapy for Head and Neck Squamous Cell Carcinoma. Mol Imaging Biol (2011) 13(2):22731. doi: 10.1007/s11307-010-0365-2 
176. Grosu AL, Souvatzoglou M, Röper B, Dobritz M, Wiedenmann N, Jacob V, et al. Hypoxia Imaging With FAZA-PET and Theoretical Considerations With Regard to Dose Painting for Individualization of Radiotherapy in Patients With Head and Neck Cancer. Int J Radiat Oncol Biol Phys (2007) 69 (2):541-51. doi: 10.1016/j.ijrobp.2007.05.079

177. Souvatzoglou M, Grosu AL, Röper B, Krause BJ, Beck R, Reischl G, et al. Tumour Hypoxia Imaging With [18F]FAZA PET in Head and Neck Cancer Patients: A Pilot Study. Eur J Nucl Med Mol Imaging (2007) 34(10):1566-75. doi: 10.1007/s00259-007-0424-3

178. Servagi-Vernat S, Differding S, Hanin FX, Labar D, Bol A, Lee JA, et al. A Prospective Clinical Study of (1)(8)F- FAZA PET-CT Hypoxia Imaging in Head and Neck Squamous Cell Carcinoma Before and During Radiation Therapy. Eur J Nucl Med Mol Imaging (2014) 41(8):1544-52. doi: 10.1007/ s00259-014-2730-x

179. Grönroos TJ, Lehtiö K, Söderström KO, Kronqvist KO, Laine KO, Eskola KO, et al. Hypoxia, Blood Flow and Metabolism in Squamous-Cell CarciNoma of the Head and Neck: Correlations Between Multiple Immunohistochemical Parameters and PET. BMC Cancer (2014) 14:876. doi: 10.1186/1471-2407-14-876

180. Maity A, Lin A. Using [18f]EF5 PET to Measure Hypoxia Modulation by Nelfinavir in Larynx Cancer. Philadelphia: National Institute of Health, University of Pennsylvania (2014)

181. Chao KS, Bosch WR, Mutic S, Lewis JS, Dehdashti F, Mintun MA, et al. A Novel Approach to Overcome Hypoxic Tumor Resistance: Cu-ATSMGuided Intensity-Modulated Radiation Therapy. Int J Radiat Oncol Biol Phys (2001) 49(4):1171-82. doi: 10.1016/s0360-3016(00)01433-4

182. Eschmann SM, Paulsen F, Reimold M, Dittmann H, Welz S, Reischl G, et al. Prognostic Impact of Hypoxia Imaging With 18F-Misonidazole PET in NonSmall Cell Lung Cancer and Head and Neck Cancer Before Radiotherapy. J Nucl Med (2005) 46(2):253-60.

183. Gagel B, Reinartz P, Demirel C, Kaiser HJ, Zimny M, Piroth M, et al. [18F] Fluoromisonidazole and [18F] Fluorodeoxyglucose Positron Emission Tomography in Response Evaluation After Chemo-/Radiotherapy of NonSmall-Cell Lung Cancer: A Feasibility Study. BMC Cancer (2006) 6:51. doi: 10.1186/1471-2407-6-51

184. Cherk MH, Foo SS, Poon AM, Knight SR, Murone C, Papenfuss AT, et al. Lack of Correlation of Hypoxic Cell Fraction and Angiogenesis With Glucose Metabolic Rate in Non-Small Cell Lung Cancer Assessed by 18FFluoromisonidazole and 18F-FDG PET. J Nucl Med (2006) 47(12):1921-6.

185. Vera P, Bohn P, Edet-Sanson A, Salles A, Hapdey S, Gardin I, et al. Simultaneous Positron Emission Tomography (PET) Assessment of Metabolism With (1)(8)F-Fluoro-2-Deoxy-D-Glucose (FDG), Proliferation With (1)(8)F-Fluoro-Thymidine (FLT), and Hypoxia With (1)(8)FluoroMisonidazole (F-Miso) Before and During Radiotherapy in Patients With Non-Small-Cell Lung Cancer (NSCLC): A Pilot Study. Radiother Oncol (2011) 98(1):109-16. doi: 10.1016/j.radonc.2010.10.011

186. Francis RJ, Segard T, Morandeau L, Lee YC, Millward MJ, Segal A, et al. Characterization of Hypoxia in Malignant Pleural Mesothelioma With FMISO PET-CT. Lung Cancer (2015) 90(1):55-60. doi: 10.1016/ j.lungcan.2015.07.015

187. Thureau S, Chaumet-Riffaud P, Modzelewski R, Fernandez P, Tessonnier L, Vervueren L, et al. Interobserver Agreement of Qualitative Analysis and Tumor Delineation of 18F-Fluoromisonidazole and 30-Deoxy-30-18FFluorothymidine PET Images in Lung Cancer. J Nucl Med (2013) 54 (9):1543-50. doi: 10.2967/jnumed.112.118083

188. Dehdashti F, Mintun MA, Lewis JS, Bradley J, Govindan R, Laforest R, et al. In Vivo Assessment of Tumor Hypoxia in Lung Cancer With 60Cu-ATSM. Eur J Nucl Med Mol Imaging (2003) 30(6):844-50. doi: 10.1007/s00259-0031130-4

189. Havelund BM, Holdgaard PC, Rafaelsen SR, Mortensen LS, Theil J, Bender D, et al. Tumour Hypoxia Imaging With 18F-Fluoroazomycinarabinofuranoside PET/CT in Patients With Locally Advanced Rectal Cancer. Nucl Med Commun (2013) 34(2):155-61. doi: 10.1097/MNM.0b013e32835bd5bc

190. Garcia-Parra R, Wood D, Shah RB, Siddiqui J, Hussain H, Park H, et al. Investigation on Tumor Hypoxia in Resectable Primary Prostate Cancer as Demonstrated by 18F-FAZA PET/CT Utilizing Multimodality Fusion TechNiques. Eur J Nucl Med Mol Imaging (2011) 38(10):1816-23. doi: 10.1007/ s00259-011-1876-Z
191. Shetty D, Choi SY, Jeong JM, Lee JY, Hoigebazar L, Lee YS, et al. Stable Aluminium Fluoride Chelates With Triazacyclononane Derivatives Proved by X-Ray Crystallography and 18F-Labeling Study. Chem Commun (Camb) (2011) 47(34):9732-4. doi: 10.1039/clcc13151f

192. Waldron BP, Parker D, Burchardt C, Yufit DS, Zimny M, Roesch F. Structure and Stability of Hexadentate Complexes of Ligands Based on AAZTA for Efficient PET Labelling With Gallium-68. Chem Commun (Camb) (2013) 49 (6):579-81. doi: $10.1039 / \mathrm{c} 2 \mathrm{cc} 37544 \mathrm{c}$

193. Yang BY, Jeong JM, Kim YJ, Choi JY, Lee YS, Lee DS, et al. Formulation of $68 \mathrm{Ga}$ BAPEN Kit for Myocardial Positron Emission Tomography Imaging and Biodistribution Study. Nucl Med Biol (2010) 37(2):149-55. doi: 10.1016/ j.nucmedbio.2009.10.010

194. Seelam SR, Lee JY, Lee YS, Hong MK, Kim YJ, Banka VK, et al. Development of 68Ga-Labeled Multivalent Nitroimidazole Derivatives for Hypoxia Imaging. Bioorg Med Chem (2015) 23(24):7743-50. doi: 10.1016/ j.bmc.2015.11.024

195. Shimizu Y, Nakai Y, Iikuni S, Watanabe H, Nakamoto Y, Ono M. Synthesis and Evaluation of Gallium-68-Labeled Nitroimidazole-Based Imaging Probes for PET Diagnosis of Tumor Hypoxia. Ann Nucl Med (2021) 35 (3):360-9. doi: 10.1007/s12149-020-01573-5

196. Wu YK, Hao GY, Ramezani S, Saha D, Zhao D, Sun X, et al. [68ga]-HPDO3A-Nitroimidazole: A Promising Agent for PET Detection of Tumor Hypoxia. Contrast Media Mol Imaging (2015) 10(6):465-72. doi: 10.1002/ cmmi.1649

197. Dilworth JR, Pascu SI, Waghorn PA, Vullo D, Bayly SR, Christlieb M, et al. Synthesis of Sulfonamide Conjugates of $\mathrm{Cu}(\mathrm{ii}), \mathrm{Ga}$ (iii), In(iii), $\mathrm{Re}$ (v) and $\mathrm{Zn}$ (ii) Complexes: Carbonic Anhydrase Inhibition Studies and Cellular Imaging Investigations. Dalton Trans (2015) 44(11):4859-73. doi: 10.1039/ C4DT03206C

198. Sneddon D, Niemans R, Bauwens M, Yaromina A, van Kuijk SJ, Lieuwes NG, et al. Synthesis and in Vivo Biological Evaluation of 68Ga-Labeled Carbonic Anhydrase IX Targeting Small Molecules for Positron Emission Tomography. J Med Chem (2016) 59(13):6431-43. doi: 10.1021/ acs.jmedchem.6b00623

199. Li Z, Wang B, Zhang Z, Wang B, Xu Q, Mao W, et al. Radionuclide ImagingGuided Chemo-Radioisotope Synergistic Therapy Using a 131I-Labeled Polydopamine Multifunctional Nanocarrier. Mol Ther (2018) 26(5):138593. doi: 10.1016/j.ymthe.2018.02.019

200. Li XF, Sun X, Ma Y, Suehiro M, Zhang M, Russell J, et al. Detection of Hypoxia in Microscopic Tumors Using 131I-Labeled Iodo-Azomycin Galactopyranoside (131I-IAZGP) Digital Autoradiography. Eur J Nucl Med Mol Imaging (2010) 37(2):339-48. doi: 10.1007/s00259-009-1310-y

201. Riedl CC, Brader P, Zanzonico PB, Chun YS, Woo Y, Singh P, et al. Imaging Hypoxia in Orthotopic Rat Liver Tumors With Iodine 124-Labeled Iodoazomycin Galactopyranoside PET. Radiology (2008) 248(2):561-70. doi: 10.1148/radiol.2482071421

202. O’Donoghue JA, Guillem JG, Schöder H, Lee NY, Divgi CR, Ruby JA, et al. Pilot Study of PET Imaging of 124I-Iodoazomycin Galactopyranoside (IAZGP), A Putative Hypoxia Imaging Agent, in Patients With Colorectal Cancer and Head and Neck Cancer. EJNMMI Res (2013) 3(1):42. doi: 10.1186/2191-219X-3-42

203. Wen B, Burgman P, Zanzonico P, O'donoghue J, Cai S, Finn R, et al. A Preclinical Model for Noninvasive Imaging of Hypoxia-Induced Gene Expression; Comparison With an Exogenous Marker of Tumor Hypoxia. Eur J Nucl Med Mol Imaging (2004) 31(11):1530-8. doi: 10.1007/s00259004-1673-z

204. Ueda M, Kudo T, Mutou Y, Umeda IO, Miyano A, Ogawa K, et al. Evaluation of [125I]IPOS as a Molecular Imaging Probe for Hypoxia-Inducible Factor-1Active Regions in a Tumor: Comparison Among Single-Photon Emission Computed Tomography/X-Ray Computed Tomography Imaging, Autoradiography, and Immunohistochemistry. Cancer Sci (2011) 102 (11):2090-6. doi: 10.1111/j.1349-7006.2011.02057.x

205. Chrastina A, Závada J, Parkkila S, Kaluz S, Kaluzová M, Rajcáni J, et al. Biodistribution and Pharmacokinetics of 125I-Labeled Monoclonal Antibody M75 Specific for Carbonic Anhydrase IX, An Intrinsic Marker of Hypoxia, in Nude Mice Xenografted With Human Colorectal Carcinoma. Int J Cancer (2003) 105(6):873-81. doi: 10.1002/ ijc. 11142 
206. Huang H, Zhou H, Li Z, Wang X, Chu T. Effect of a Second Nitroimidazole Redox Centre on the Accumulation of a Hypoxia Marker: Synthesis and In Vitro Evaluation of 99mtc-Labeled Bisnitroimidazole Propylene Amine Oxime Complexes. Bioorg Med Chem Lett (2012) 22(1):172-7. doi: 10.1016/j.bmcl.2011.11.042

207. Li N, Zhu H, Chu T-W, Yang Z. Preparation and Biological Evaluation of 99mtc-N4IPA for Single Photon Emis- Sion Computerized Tomography Imaging of Hypoxia in Mouse Tumor. Eur J Med Chem (2013) 69:223-31. doi: 10.1016/j.ejmech.2013.08.005

208. Giglio J, Fernández S, Pietzsch HJ, Dematteis S, Moreno M, Pacheco JP, et al. Synthesis, In Vitro and In Vivo Characterization of Novel 99mtc-'4+1'Labeled 5-Nitroimidazole Derivatives as Potential Agents for Imaging Hypoxia. Nucl Med Biol (2012) 39(5):679-86. doi: 10.1016/j.nucmedbio.2011.12.012

209. Huizing FJ, Garousi J, Lok J, Franssen G, Hoeben BAW, Frejd FY, et al. CAIX-Targeting Radiotracers for Hypoxia Imaging in Head and Neck Cancer Models. Sci Rep (2019) 9(1):18898. doi: 10.1038/s41598-019-54824-5

210. Zhou Z, Wagh NK, Ogbomo SM, Shi W, Jia Y, Brusnahan SK, et al. Synthesis and In Vitro and In Vivo Evaluation of Hypoxia-Enhanced 111In-Bombesin Conjugates for Prostate Cancer Imaging. J Nucl Med (2013) 54(9):1605-12. doi: 10.2967/jnumed.112.117986

211. Carlin S, Khan N, Ku T, Longo VA, Larson SM, Smith-Jones PM. Molecular Targeting of Carbonic Anhydrase IX in Mice With Hypoxic HT29 Colorectal Tumor Xenografts. PloS One (2010) 5(5):e10857. doi: 10.1371/ journal.pone.0010857

212. Das T, Chakraborty S, Banerjee S, Mukherjee A, Samuel G, Sarma HD, et al. Preparation and Preliminary Biological Evaluation of a 177Lu Labeled Sanazole Derivative for Possible Use in Targeting Tumor Hypoxia. Bioorg Med Chem (2004) 12(23):6077-84. doi: 10.1016/j.bmc.2004.09.007

213. Hoeben BA, Kaanders JH, Franssen GM, Troost EG, Rijken PF, Oosterwijk E, et al. PET of Hypoxia With 89Zr-Labeled Cg250-F(Ab')2 in Head and
Neck Tumors. J Nucl Med (2010) 51(7):1076-83. doi: 10.2967/ jnumed.109.073189

214. Amarnath C, Laurence C, Eric OA. Molecular Mechanisms of Hypoxia in Cancer. Clin Trans Imaging (2017) 5:225-53. doi: 10.1007/s40336-017-0231-1

215. Fleming IN, Manavaki R, Blower PJ, West C, Williams KJ, Harris AL, et al. Imaging Tumour Hypoxia With Positron Emission Tomography. $\mathrm{Br} J$ Cancer (2015) 112:238-2500. doi: 10.1038/bjc.2014.610

216. Zeng Y, Ma JW, Zhang SJ, Wu D. Imaging Agents in Targeting Tumor Hypoxia. Curr Med Chem (2016) 23(17):1775-800. doi: 10.2174/ 0929867323666160321122023

Conflict of Interest: Authors SF, YC, JW was employed by company Academician (Expert) Workstation of Sichuan Province.

The remaining authors declare that the research was conducted in the absence of any commercial or financial relationships that could be construed as a potential conflict of interest.

Publisher's Note: All claims expressed in this article are solely those of the authors and do not necessarily represent those of their affiliated organizations, or those of the publisher, the editors and the reviewers. Any product that may be evaluated in this article, or claim that may be made by its manufacturer, is not guaranteed or endorsed by the publisher.

Copyright (c) 2021 Huang, Fan, Li, Fu, Chen and Wu. This is an open-access article distributed under the terms of the Creative Commons Attribution License (CC BY). The use, distribution or reproduction in other forums is permitted, provided the original author(s) and the copyright owner(s) are credited and that the original publication in this journal is cited, in accordance with accepted academic practice. No use, distribution or reproduction is permitted which does not comply with these terms. 